Florida International University FIU Digital Commons

$11-21-2006$

\title{
Myrothecium verrucaria : a potential biological control agent for the invasive 'old world climbing fern' Lygodium microphyllum
}

Tainya Cathia Clarke

Florida International University

DOI: $10.25148 /$ etd.FI14060851

Follow this and additional works at: https://digitalcommons.fiu.edu/etd

Part of the Environmental Sciences Commons

\section{Recommended Citation}

Clarke, Tainya Cathia, "Myrothecium verrucaria : a potential biological control agent for the invasive 'old world climbing fern' Lygodium microphyllum" (2006). FIU Electronic Theses and Dissertations. 2381.

https://digitalcommons.fiu.edu/etd/2381 
FLORIDA INTERNATIONAL UNIVERSITY

Miami, Florida

MYROTHECIUM VERRUCARIA - A POTENTIAL BIOLOGICAL CONTROL AGENT FOR THE INVASIVE 'OLD WORLD CLIMBING FERN'

LYGODIUM MICROPHYLLUM

A thesis submitted in partial fulfillment of the

requirements for the degree of

MASTER OF SCIENCE

in

ENVIRONMENTAL STUDIES

by

Tainya Cathia Clarke 
To: Interim Dean Mark Szuchman

College of Arts and Sciences

This thesis, written by Tainya Cathia Clarke, and entitled Myrothecium verrucaria - A Potential Biological Control Agent for the Invasive 'Old World Climbing Fern' Lygodium microphyllum, having been approved in respect to style and intellectual content, is referred to you for judgment.

We have read this thesis and recommend that it be approved.

Michael Ross

Anne Hartley

Krishnaswamy Jayachandran, Major Professor

Date of Defense: November 21, 2006

The thesis of Tainya Cathia Clarke is approved.

Interim Dean Mark Szuchman College of Arts and Sciences

Dean George Walker University Graduate School

Florida International University, 2006 


\section{ACKNOWLEDGMENTS}

I wish to express sincere gratitude to Dr. Kateel Shetty whose knowledge of fungal isolation and culture was helpful throughout this study. Thank you to my professors Krish Jayachandran, Michael Ross and Anne Hartley for their assistance in preparation of this manuscript. Thanks to Marnie Billie and Alyssa Jacobs of the Big Cypress Seminole reservation, Dennis Giardina of the Panther National Wildlife Refuge and David Black of the Dupuis State preserve for their assistance with collecting Lygodium samples. I also thank Jack Fisher of Fairchild's Tropical Botanical Gardens for his generous donation of native plants used throughout this study, Michael Lott and Min Rayamajhi (University of Florida) for their assistance in plant identification, sampling techniques and sourcing information during the initial stages of research and Alan Meerow for assistance with the growth chambers at the USDA. 
ABSTRACT OF THE THESIS

MYROTHECIUM VERRUCARIA - A POTENTIAL BIOLOGICAL CONTROL AGENT

FOR THE INVASIVE 'OLD WORLD CLIMBING FERN'

LYGODIUM MICROPHYLLUM

by

Tainya Cathia Clarke

Florida International University, 2006

Miami, Florida

Professor Krishnaswamy Jayachandran, Major Professor

Non native plants are a threat to ecosystems across the globe, some delicate ecosystems like those in South Florida are in greater danger because of the large number of endemics at risk. Old World Climbing Fern (Lygodium microphyllum) has become one of the most invasive and destructive weeds in southern Florida. To date different efforts have been made to control its growth and spread but have not been successful. In light of the highly delicate ecosystem affected by L. microphyllum, a biological paradigm may be a more ecologically sound approach to the containment of this obnoxious weed. The fungus Myrothecium verrucaria, has been identified as a possible bioherbicide against $L$. microphyllum. A series of greenhouse studies demonstrated that $M$. verrucaria serves as an effective biocontrol agent against $L$. microphyllum severely affecting over $75 \%$ of ferns while having very little impact on non target plants (less than $5 \%$ infected, none severely). This type of biocontrol strategy to restore native ecosystems is cost effective and environmentally friendly. 


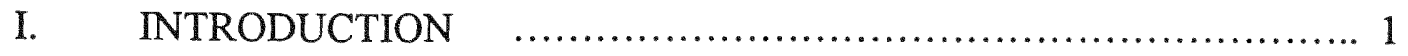

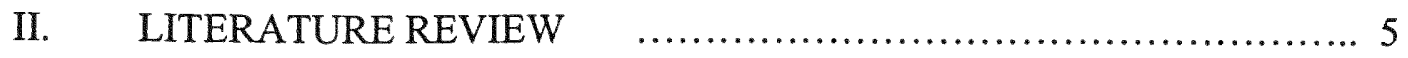

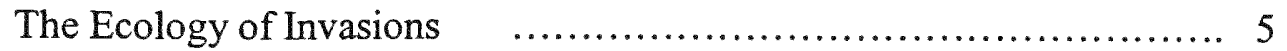

Life history and phylogeny of Lygodium microphyllum $\quad$............. 8

Research purpose $\quad$............................................... 11

Biological control $\quad$............................................. 12

Biological controls versus Synthetic herbicides $\quad$..................... 14

Myrothecium verrucaria $\quad$........................................ 17

Field sites $\quad$.................................................... 18

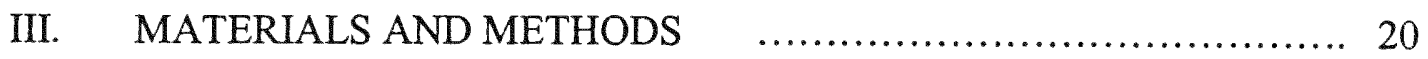

Plant Materials $\quad$................................................ 20

Preparation of Inoculum $\quad$...................................... 21

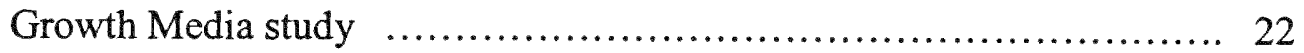

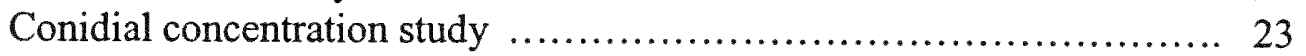

Host specificity study ............................................ 23

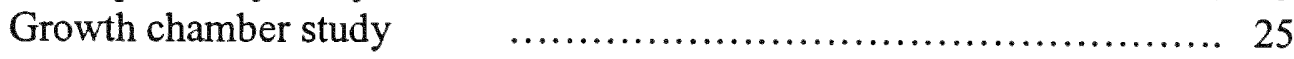

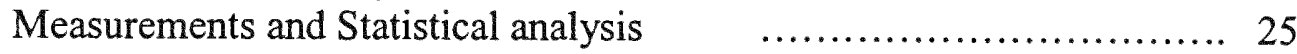

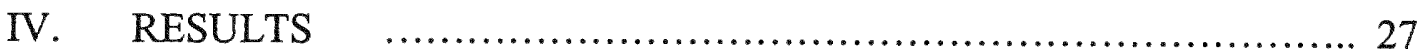

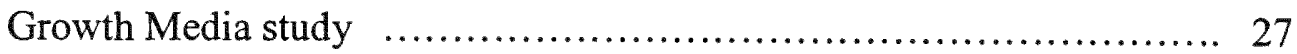

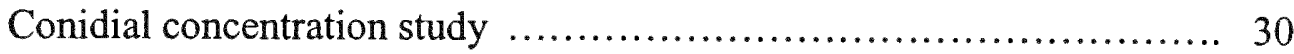

Host specificity study .......................................... 34

Growth chamber study $\quad$..................................... 37

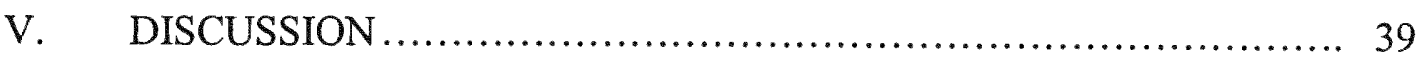

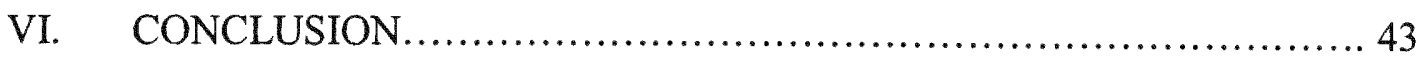

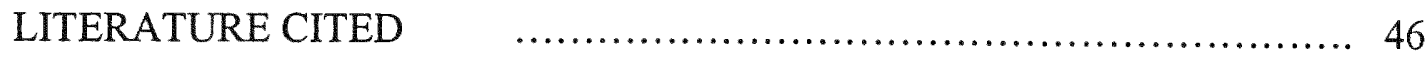

APPENDICES $\quad$................................................ 53 
1. Lygodium microphyllum invading a Cypress stand at Big Cypress Seminole Indian Reservation

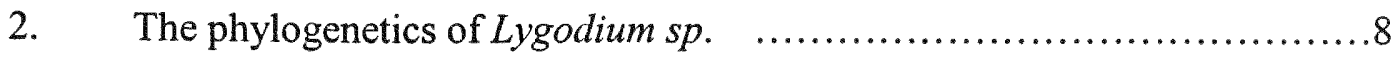

3. Bar chart illustrating the comparative growth of $M$. verrucaria on different growth media

4. Myrothecium on a $100 \%$ PDA plate 21 days after inoculation

5. The effect of varying conidial concentrations of Myrothecium verrucaria on disease development (average number of infected leaves/plant) in Lygodium microphyllum

6. Infection efficiency of Myrothecium verrucaria conidial concentrations on Lygodium microphyllum

7. Disease indices of Lygodium microphyllum inoculated with two concentrations of Myrothecium verrucaria

8. Disease indices of native plant species inoculated with two concentrations of Myrothecium verrucaria 


\section{INTRODUCTION}

The problem area is South Florida, a region rich in biodiversity and endemic plant species. S. Florida is comprised of dense forests and grasslands whose environments vary in temperature, light intensity and humidity. Over the last few decades the state of Florida has been the nexus for the importation of hundreds of exotic species, and invasion by exotic plants and animals has been a constant threat to the native community. There are several plant species that are most dangerous in this regard, and considered as "biological pollutants"; among these, are two non-native ferns $L$. microphyllum (Cavanilles) R Brown) and L. japonicum (Thunb. ex Murr.) Sw, listed as noxious weeds in 1999 by the Florida Department of Agriculture and Consumer Services (FDACS). (Ferriter, 2001). Both were imported as ornamentals by horticulturalists. $L$. microphyllum is considered the fourth most invasive category I exotic plant species in South Florida (Langeland, K.A. 1998; Van Driesche et al 2002). Recorded in 9 out of 67 counties in Florida, this non-native fern has invaded tree islands, cypress wetlands (Langeland, K.A. 1998) and even areas lacking vertical support, such as grasslands and ditches. L. microphyllum usually invades moist habitats, but can be found in areas with a short hydroperiod and very little soil moisture (personal observation). L. microphyllum is a non-indigenous climbing fern which overruns plants capable of providing physical support. It may blanket the vegetation causing death to the mature canopy and sub canopy (Roberts 1996, 1997). Over the last three decades (Ferriter, 2001) the growth of L. microphyllum has extended as far north as Polk County, the northern most region of USDA Plant Hardiness Zone 10a. According to aerial surveying done by the South 
Florida Water Management District, the fern expanded its range from about 30,000 acres to 150,000 acres between 1993 and 2003. At this rate of growth and spread, by 2009 every plant community south of Lake Okeechobee will be infested with L. microphyllum, which has the potential to negatively impact the proposed $\$ 8.4$ billion Everglades restoration efforts.

In its early growth stages, new fronds form a thick mat at the ground surface, smothering and stifling native herbs and tree seedlings (Ferriter, ed. 2001). L. microphyllum has no natural enemies in South Florida; as a result it has remained successful as an invasive species.

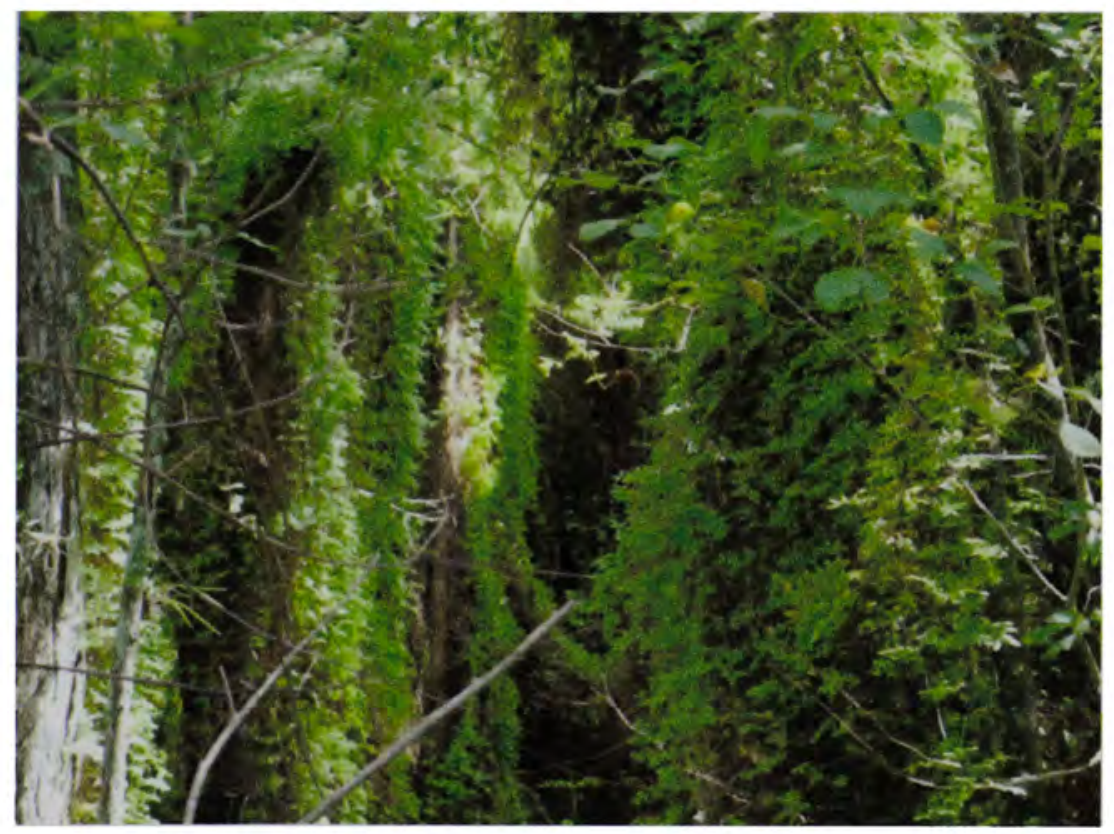

Figure 1. Lygodium microphyllum invading a Cypress stand at Big Cypress Seminole Indian Reservation 
The purpose of the research reported here is to investigate a possible biological method capable of controlling and/or eliminating L. microphyllum from the forested areas of S. Florida in order to ensure the viability and survival of native plants species. This research is important because of the need to eliminate the use of synthetic and /or organic herbicides in Florida due to the close association between plant and animal species. South Florida is relatively flat with a gentle slope southwards and a hydroperiod, which may be as short as 4 months or flooded all year long (Lodge, 1998). Dominated by the Everglades, aquatic environments occupy over $70 \%$ of the land area in South Florida, providing a habitat for many endangered, endemic and transient species, and as such require protection from toxic applications of herbicides.

The aquifers in South Florida are close to the surface, and supply residents with millions of gallons of water daily. Contamination of these drinking reserves therefore pose a health risk to the almost four million persons living in South Florida. The Everglades ecosystem has an underlying soil composition of muck, peats and fresh water marl (Stone and Chmura 2004), a far cry from the sandy soils of central and northeastern south Florida, yet $L$. microphyllum grows luxuriantly among native plant communities throughout the state. A range of herbicides has been used in the control of non-native Lygodium sp.; Pathfinder II, Rodeo (Dennis Giardina pers. comm., Ferriter ed. 2001), Glyphosate (Thomas and Brandt 2003), Arsenal, Garlon and Escort (Ferriter ed. 2001, Miller 2003). Some of these herbicides are approved for wetland areas while others have detrimental effects associated with such applications. 
The use of a biological control could eliminate many of the risks associated with using synthetic herbicides in this region. Biological control is cost-effective and does not usually pose an environmental threat/pollution. Biological control is desirable because of the growth habit of L. microphyllum, which entwines itself around native vegetation, making it difficult to use fires or general herbicide applications as control techniques. Flooding may lead to a reduction in the density of young plants or sporelings germinating in the field, but since spores are not affected by water saturation, an explosion of growth of this fern can be expected as the water recedes and bare ground is exposed. It is important to identify a specific control agent with a narrow host range that will not be detrimental to native plant species. Biological controls usually have a high level of selectivity (Charudattan 2001), while the use of fire and herbicides is often non-selective. Given the uncontrolled growth and spread of Lygodium it has become critical to find biological control agents that can be used to reduce the competitiveness and spread of the weed in Florida. At present no plant pathogen specific to L. microphyllum with biocontrol potential is available. However, a mycoherbicide Myrothecium verrucaria has been successfully used in the control of invasive plants such as leafy spurge (Yang and Jong, 1995a) and kudzu (Boyette et al. 1999). M. verrucaria is native to the soils of the southern United States, and is a facultative parasite that can be found in many plant species ( Domsch et al 1980). In the absence of a Lygodium specific native microbial biocontrol agent, we wanted to test the effectiveness of $M$. verrucaria on $L$. microphyllum, as the use of a mycoherbicide in the control of $L$. microphyllum may prove to be a practical and ecologically safe weed management method. 


\section{LITERATURE REVIEW}

\section{The Ecology of Invasions}

Nonnative species may thrive in recipient communities due to the absence of their native predators (Losos et al. 1997, Weber and Schmid 1998, Lee 2002). This liberation from natural enemies could contribute to the evolution of larger plants ${ }^{1}$ and/or greater fecundity (Maron et al. 2004), which contributes to plant competitiveness. Blossey and Nöltzold (1995) and Siemann and Rogers (2003) suggest that competitive ability of invasives may become increased as they expend less energy and resources on defense in the absence of enemies; this is referred to as the evolution of increased competitive ability (EICA). This ability may present itself in the production of a greater amount of spores or reproductive organs, in constant reproduction instead of seasonal, or in faster growth rates and plant size.

Insufficient systematic records of events (Elton, 1958) make it difficult to determine when and how many invasive species entered North America and other continents. Recent history, however, documents the importation of some plants and animals for agricultural and ornamental purposes during the time period of early settlers. Nonnatives have long been favored as desirable plants for highway landscaping and erosion management and prevention ( $\mathrm{M}^{\mathrm{c}}$ Arthur et al, 1990). The basis for the problem of nonnative imports is a social one. Many plants were imported accidentally via vessels transporting people, or goods tainted with seeds and plant parts. Some plants were imported intentionally for economic/agricultural reasons, or to appease the aesthetics of gardening enthusiasts and horticulturalists. The horticulture industry alone has imported

\footnotetext{
'Plants channel resources that would have been used for defense into growth and reproduction.
} 
hundreds of taxonomically diverse species during the latter part of this century. Other introductions were accidental; seeds and spores were often transported from one region to the next by strong wind and air currents associated with storm events.

L. microphyllum is considered a weed because it grows rapidly and competes with plants of economic value. As a potted fern or garden trimming, Lygodium $s p$ serve as ornamentals, L. microphyllum does not posses any physical properties of interest to the furniture or craft industry in Florida, though in its native range of Southeast Asia it has been used in combination with other ferns of the Calamus sp. for basket weaving (People and Plants online). Both non-native Lygodium sp. pose a threat to the native L. palmatum, by inhabiting areas where it would grow. Successful invaders have been known to alter soil microbial communities and other soil conditions (Kourtev et al. 2002). It is quite possible that both L. microphyllum and L. japonicum are altering the soils of South Florida making them less conducive to the growth of native plant species.

While L. japonicum's growth is extending southwards, L. microphyllum's growth is extending westwards and northwards (Ferriter (ed) 2001) which means it can endure temperatures as low as $25^{\circ} \mathrm{F}\left(-1.2^{\circ} \mathrm{C}\right)$ [zone 9]. According to the plant hardiness zone map (USDA Publication 1990), this zone extends up to N Florida and parts of Georgia (Appendix XIII). This suggests that if L. microphyllum growth, reproduction and dispersal increase in this temperature range there may be no stopping its spread towards the northern edge of the zone. Large mats of L. microphyllum has been found in areas of very little to no human disturbance e.g. many tree islands along the southwest coast (Michael Norland pers. comm.) and inundated forests at Dupuis State Preserve (David Black pers. comm.) No one is sure how the plant became established in these areas, and 
while spore dispersal models lend some understanding of where and how spores can disperse from an established mat, there is insufficient data to indicate why the fern germinates in some areas and not others, even though the species is capable of occupying a wide range of habitats.

Success in controlling invaders is dependent on a composite assessment of all species in the affected area and their interactions, not a fight against a particular species (Simberloff et al. 1997) We need to make native ecosystems less receptive to invasions by trying to best preserve natural processes. It is unlikely that an invasive can be removed entirely from an ecosystem, but a sound management plan involving reestablishment of natives and systematic recovery of soil biota and nutrient availability should lead to the perpetuation of an ecosystem in a fairly natural and diverse state.

\section{Life history and phylogeny of Lygodium microphyllum}

Plants from the phylum Pteridophyta have very little agricultural and pharmaceutical value. As such they are usually viewed as pests, unwanted competitors of economically valuable species or fast growing weeds that may have deleterious effects on desired species (Croft 1982). Fern growth differs among genera; some are herbaceous, forming branches from the ground eg. the Giant leather fern, some grow as trees e.g. Cyathea sp. and others as vines, such as the Lygodium species under study in this paper.

There have been disagreements among botanists concerning the correct classification of families of the phylum pteridophyta. Some literature place Lygodium sp. in the family Schizaeceae while others place them in a family of their own, the 
Lygodaceae. I have chosen to adopt the former, which is the more popular classification. This phylogeny is illustrated in the figure below.

Figure 2. The phylogenetics of Lygodium sp.

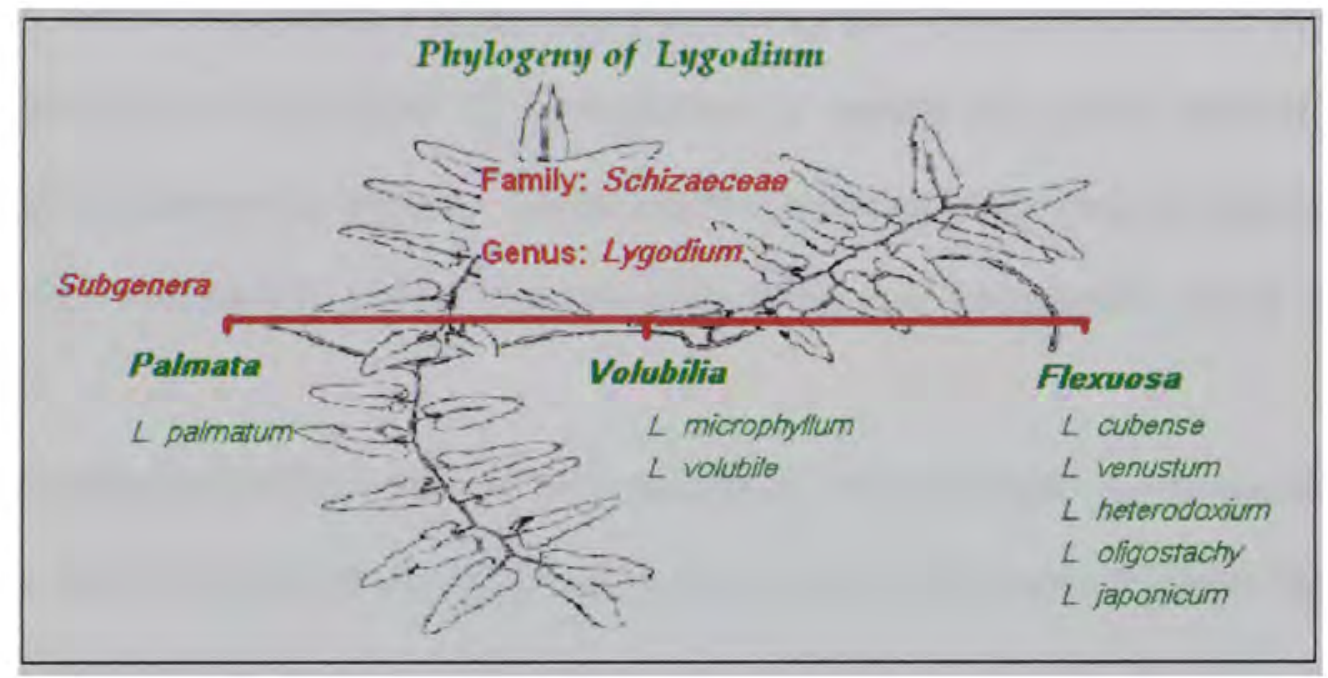

Native to Australia, Asia and Africa, and capable of growing to 100ft, Lygodium microphyllum is one of the tallest pteridophytes in North America (Wagner and Smith 1993). It possesses leaves capable of extensive growth. The vine-like leaves wrap around trees, light poles and other vertical structures (personal observation) and may extend up to the pinnacle of these structures and then grow downwards. Lygodium microphyllum does not display true secondary growth; field studies have revealed that seemingly new plants are often extension of multiple leaf rachises connected by an extremely long underground stem. The fern is therefore capable of producing a dense network of stem and roots below ground and stem and leaves above ground. The stems are true rhizomes, and because all the leaves/foliage above ground may be part of a single plant, it is not possible to age mature plants present in the field. 
Leaves of L. microphyllum are very ornate. They are light green during spring to summer, turning a dark green then brown during December to February. Fronds are palmately lobed and measure 2 to $3.5 \mathrm{~cm}$ long and 1.5 to $2 \mathrm{~cm}$ wide. The young sporelings have fronds arranged in a dichotomous manner and often differ in appearance to mature leaves. Sporophytes and gametophytes actively grow year round (Ferriter 2001) hence the vine is ever present. L. microphyllum is capable of several methods of reproduction: vegetative propagation via the creeping rhizomes which may sometimes be decades old, intragametic selfing (Ferriter (ed) 2001), and intergametic selfing and crossing.

Crossing and selfing occur via spore production. The sporangia ${ }^{2}$ may be found on the under side of mature fronds, appearing as small brown balls along the edges. These balls are only 10's of $\mu \mathrm{m}$ in diameter and may be difficult to see with the naked eye. Spores may be dispersed by wind and water, or transferred from one place to another by attaching themselves to animal hairs and feathers or clothes and shoes worn by humans that come in contact with them. Lygodium's competitive ability may thus be attributed to its multifaceted reproduction as well as rapid growth rate to reproductive age. In researching the reproductive biology of L. microphyllum and L. japonicum, Lott et al. (2003) concluded that both species would continue to spread throughout Florida and potentially other countries with a suitable climatic regime.

The growth pattern of Lygodium is puzzling to many south Florida ecologists. There are several ecological models which use distance from origin and wind patterns to predict the dispersal of L. microphyllum spores (Duke Sylvester (pers. comm.). If the

\footnotetext{
${ }^{2}$ The spore-producing organ of pteridophytes is the sporangium, $p l$. sporangia.
} 
models are correct there remains the question as to what are the controlling factors of Lygodium's spread once it has invaded an area. Why is it present in patches and not one large area of infection? Differences in climate, soil type and resident pathogens may be attributes which determine whether or not L. microphyllum invades one habitat and not another. The growth and reproductive rate of any plant may be significantly increased if the plant is located in an area of optimal conditions. Plants can exceed their normal height, population density and reproductive capacity as they assimilate the nutritive conditions around them and channel more energy into growth and reproduction.

\section{Research purpose}

L. microphyllum has become invasive and damaging to native flora in S. Florida, perhaps due to lack of natural enemies. M. verrucaria has been successful in the control of invasive plants such as leafy spurge and kudzu, and has been used with L. japonicum, which is related to L. microphyllum. With the significant physiological and genetic similarities between these two hosts, the effect of $M$. verrucaria on both may be similar. L. microphyllum occurs in different habitats of varying temperature, light and humidity. It may be more susceptible to $M$. verrucaria under some subset of these conditions. The research will therefore test its susceptibility under different levels of light and humidity. The use of $M$. verrucaria would reduce the detrimental changes of structure and function (productivity, diversity, and stability of representative communities) of ecosystems by synthetic chemicals.

Because L. microphyllum occupies a wide range of habitats, there is a large number of non-target species that may be affected by field application. The possibility of 
severely affecting non-target hosts is great (Yang and Jong 1995a) and it is impossible to test all non-target species that might be affected. Two non-target species from each habitat in which $L$. microphyllum is a significant problem in south Florida will be tested against $M$. verrucaria: This will be carried out in the hope that there will be some indication of the host specificity of $M$. verrucaria host range determination. If successful in greenhouse studies, the fungus will be used in small field studies to examine the spread from L. microphyllum to non-target hosts and the effect of direct application of fungus on these non-target plants.

Lygodium microphyllum is a suitable candidate for biological control in south Florida because it grows in a wide range of habitats in close proximity to several species of native plants and animals (personal observation), hence general/non-target herbicides are not recommended for its control. Moreover, a variety of natural enemies have been associated with $L$. microphyllum in its native range.

\section{$\underline{\text { Biological Control }}$}

The use of mycoherbicides in biocontrol was developed by plant pathologists in Florida and Arkansas (Templeton 1982). Fungal pathogens are artificially cultured, or spores are collected and may be combined with an inert carrier for application purposes. Effective and successful mycoherbicides may be patented, commercially produced and marketed (Bowers 1982). In natural ecosystems the aim of biocontrol is to restore the system to its native habitat constituents.

The use and effects of a biological control is often irreversible, as most agents used are self-dispersing and may remain effective for an extended period after 
applications (Barrett 2000). Predicting the success of a biological control involves a series of prerelease or quarantine experiments. One of the biggest concerns when dealing with a biological control is its host specificity, i.e. how many if any non-target organisms will be affected. The chosen biological control agent should not show a wide range of effects in its native environment. In early biological control efforts, not many tests included pre-release testing on non-target hosts that may be at risk of infection from the control agent (Waage 1997). In fact, some ecologists attribute a high failure rate of control programs to inadequate testing (Lockwood 1993, 1996). Today a variety of prerelease and post release studies are included in any biological control monitoring plan.

In this study our target plant (L. microphyllum) grows in close association with a wide variety of ferns and other plants. It is therefore necessary to test the pathogenicity of M. verrucaria on some ${ }^{3}$ of the plants found in habitats commonly infested with $L$. microphyllum. To establish a scale for host range specificity, the phytopathogen must be tested on plants closely related to the target plant as well as distantly related plants (Wapshere 1974). Invasive plants are good candidates for biological control if they have a narrow taxonomic range ${ }^{4}$. L. microphyllum has only one congener in South Florida; $L$. japonicum hence biological control should be an acceptable approach to curbing and eliminating this unwanted fern (Pemberton 1998).

The approach taken in the following series of experiments is referred to as classical biocontrol. This form of biocontrol has faced a lot of criticism regarding host specificity and undesirable environmental effects (McEnvoy and Coombs 1999).

\footnotetext{
3 To determine its efficacy on a broader spectrum of plants.

${ }^{4}$ Not many closely related species are present in the area.
} 
Classical biocontrol is the introduction of alien/non-native species to control other alien/ non-natives that have become invasive. Some ecologists are skeptical about this approach and surmise that the control agent may become an invasive species itself. Hence we test for host specificity, thereby providing some assurance that the chosen biological control will suppress the target organism without harmful effects on native or non-target organisms. Charudattan (1982) emphasizes the importance of seeking information on insects and pathogens associated with target (host) plants in their native range. This provides some preliminary idea of host response. However, plants may be more resistant or more susceptible to such pathogens and/or insects in an environment other than their own. The optimum biocontrol agent would be one native to South Florida but no appropriate controls have been found. The phytopathogen chosen, Myrothecium verrucaria, comes from the sicklepod plant found primarily in the southeastern United States and should not have a significant effect on native South Florida species. Bossard and Rejmánek (1994) showed that introduced pathogens sometimes cause fewer nontarget infections outside of their natural range than within their native areas. The United States Department of Agriculture (USDA) is currently conducting pre-release testing on a variety of snout mouth caterpillars that are native to Australia and S.E. Asia. The mature stages of these fern-feeding insects are pale colored moths with a wingspan of $1 / 2$ inch (Solis, Yen and Goolsby 2004). Even with years of host range tests and small scale field studies there is some skepticism of the probable negative effects these insects may have in the wider environment.

In investigating the probable success of a phytopathogen one should consider the suitability of the prevailing climate in the introduced area: will the temperature and 
humidity be conducive to the growth and effectiveness on the target plant? Do the potential benefits outweigh the potential harm to the environment? Harmful organisms can lead to further loss of native biodiversity and interrupt natural ecosystem processes (Levin 1998, Levin 1990). Some ecologists and invasive species biologists point out the difficulty of determining the host specificity of classical control agents, especially since greenhouse and laboratory tests may produce different results when compared to field studies. Tenner (1996) refers to the chronic and scattered problems of biological control as the 'revenge effect' and emphasizes the importance of long-term studies prior to field use.

\section{Biological controls versus Synthetic herbicides}

In the conventional approach successful applications of a plant pathogen seek to apply large amounts of inoculum in order to disperse from one target plant to another (Shrum 1982) and survive unfavorable environmental conditions. This means that the pathogen will likely remain within the treatment area long after application. Because of the complex interactions of organisms within ecological communities, the consequences of environmental contamination are not usually noticeable until significant damage has been done (Cairns, Niederlehner and Smith 1995). Similarly, damage to ecosystems caused by herbicidal applications are often the result of cumulative deposition, and in order to alleviate the problem a series of tests and toxicological evaluations need to be performed. Tests identify the ecosystems and organisms at risk, and the kind and extent of the effect; these studies sometimes take years to complete. The use of a biological agent would reduce the need for monitoring the fate (cumulation, bioconcentration, 
disappearance) and transport in ecological communities, and studying the effects, direct and indirect, of toxins on living organisms. The use of synthetic chemicals often result in genetic and physiological changes as well as mortality in organisms, while the use of natural pathogens would reduce these risks.

At the Arthur R Marshall Loxahatchee National Wildlife Reserve a study on the treatment and regrowth of $L$. microphyllum proved to be partially successful but very expensive. $5 \%$ Glyphosate and a surfactant were used to treat Lygodium that had been manually cut, the weed responded to treatment and after three years there was a noticeable increase in the percentage cover of native plants (Thomas and Brandt 2003). However, 3 years later Lygodium regrowth was observed in all vegetative layers of this multi-tiered ecosystem in several tree islands. Minimal damage was done to some native plants including ferns found in close proximity to Lygodium, but the damage to natives was not substantial enough to mask the success of the treatment. There was no report of effects on aquatic organisms in the area, but the Journal of Pesticide Reform herbicide fact sheet indicates that Glyphosate herbicides cause damage to the immune system in fish as well as abnormal development and genetic irregularities in fish and frogs. Lab studies as well as investigations of persons exposed to Glyphospates show increased risks of the cancer, non-Hodgkin's lymphoma, miscarriages, and attention deficit disorder.

Glyphosate is not one of the pesticides being studied by the U.S. Geological Survey's (USGS's) National Water-Quality Assessment Program, so there are no comprehensive national statistics about contamination of rivers and streams by this product. With a half life of 2 to 174 days (Glyphosate Herbicide fact sheet 2004), its fate and transport in soils provide sufficient cause for concern regarding hazardous effects on 
organisms, and pose a concern as well for chronic human exposure or contact. It has a high affinity for soil particles, this adsorption increases with an increase in clay content, cation exchange capacity, decreasing soil $\mathrm{pH}$ and phosphorous content (Sprankle et al. 1975a,b; Hance 1976; Nomura \& Hilton 1977; Rueppel et al. 1977; Glass 1987).

Garlon 3A (tryclopyr) is used for treating a wide range of broad leaved weeds in aquatic ecosystems and has no swimming or domestic livestock restrictions (Extonet Garlon 1996). However an environmental assessment of silvicultural treatments in the Apalachian mountains indicated that treatment of noxious weeds with this compound is not allowed within 30 to $100 \mathrm{ft}$ of lakes and domestic waterways (USDA Silviculture 2003, Mandy et al. 2001). The assessment stipulates that there is no risk to contamination of water by the active ingredient, as glyphosate binds to soil and has no leaching ability. While these chemicals pose no direct risk to aquatic ecosystems and resident organisms, there should be concern about effects when areas with relatively short hydroperiods or shallow surface water begin to dry out. The risk assessment concludes that there is a risk of adverse effects to local populations of birds, reptiles and small mammals if large areas are treated.

These are just two of several herbicides that pose some risk to birds and other organisms, but are approved for use in aquatic environments because the effect incurred is not directly linked. It would be prudent to use a biological control with less associated risks than any of the above-mentioned herbicides. 


\section{Myrothecium verrucaria}

Fungi are appealing as biological control agents because of their host specificity, efficient dispersal and ease of culturing (U.S. Dept. of Agriculture 1978). Myrothecium verrucaria is a soil fungus native to Louisiana and the Mississippi region. It was chosen for this study because of it was discovered to be the cause of infection on L. japonicum, a close relative of $L$. microphyllum. The $M$. verrucaria strain used for this study was isolated from L. japonicum by C. Douglas Boyette of the USDA- ARS $^{5}$ Southern Weed Science research unit in Stoneville, Mississippi. Being native to the southern United States, it should have a less harmful effect on the native species of South Florida in comparison to an introduced species from the same region as the target plant.

Myrothecium has been used in the control of Kudzu in Georgia (Lyn Walker pers. comm.), as well as other highly problematic invasives across the United States such as Leafy spurge (Yang and Jong 1995a.). There is an ongoing debate on the danger of the toxins produced by Myrothecium. Though there have been reports of mycotoxin production by some strains of $M$ verrucaria (Mortimer et al. 1971), several studies have shown that isolates vary in toxicity and that verrucarin ${ }^{6}$ is usually a weak pathogen (Walker and Tilley 1997). There has been no report of adverse reactions to the fungus among biologists exposed to $M$. verrucaria in laboratory studies in the United States.

\section{$\underline{\text { Field Sites }}$}

L. microphyllum sporelings were collected from 3 locations in South Florida (Appendix XIV) to ensure genetic variability among plants used in the experiment. Plants

\footnotetext{
${ }^{5}$ United States department of agriculture - Agricultural Research Service

${ }^{6}$ Toxin produced by $M$. verrucaria
} 
were collected from the Big Cypress Seminole Reservation, the Florida Panther National Wildlife Refuge and Dupuis State Preserve. Two of these sites are located in the southwest part of the state, while the third is located at the northernmost part of South Florida. The three areas differ in hydroperiod, light levels and dominant plant species.

According to the South Florida Ecosystem Restoration land acquisition update 2002, Dupuis State Preserve is located in north Palm Beach County and southern Martin county, nestled in the center of the northernmost part of south Florida. It spans 21,875 acres. The dominant plant species found in this area are the Slash pine (Pinus elliottii) and Saw palmetto (Serenoa repens) which characterize the Pine Rocklands of South Florida. Though the Preserve is approximately 13 feet above sea level ${ }^{7}$, and is located more than 30 miles from the nearest coast, the soil is mostly sandy and in some areas ${ }^{8}$, water percolates to the lower horizons due to the large pore spaces in the A horizon. This area has a short hydroperiod, thus surface soils are low in moisture.

At Dupuis, L. microphyllum has been observed growing over dense clumps of low-lying saw-palmettos and up and around the trunks of Slash pines. In some areas $L$. microphyllum fiddleheads grow through a dense cover of pine needles. In this case, the soil tends to be xeric and slightly acidic where the sporelings are collected, with a fairly frequent fire occurrence. In places, Lygodium prevails as an exotic species, competing for nutrients and sunlight. The plant was unintentionally introduced to the preserve and is found in patches overrunning trees near horse trails and dirt roads. The fern forms dense mats as its stems and rachis run along the ground and over low-lying palmettos, or drapes

\footnotetext{
${ }^{7}$ Based on an overview of the Loxahatchee River Basin

${ }^{8}$ Area is the southernmost region of the Central Lake District which a mixture of Myakka fine sand and permeable sands.
} 
itself like a curtain from the tops of cabbage palms and pine trees to the under story and eventually producing a rich tangle on the ground. Lygodium was collected from three different sites on the Preserve; an open canopy and much sunlight was characteristic of all three.

Farming has altered the natural vegetation (Dalrymple et al 2003) and soil moisture regime of much of South Florida. At the Big Cypress Seminole reservation (BCSR), L. microphyllum is encroaching on an orange grove, which has been drained by canals to reduce water cover on the ground. Lygodium has also been observed infesting a cypress swamp where standing water is between 4 to 18 inches deep for most of the year. At this particular site, trees are close together and light intensity is much lower than at Dupuis field sites. It is quite difficult to find the actively growing rhizome in these areas, as the rachis are so densely intertwined that sometimes following an extended stem or leaf along the ground does not always lead to a major or actively growing vine associated with roots. BCSR best illustrates the different tolerances of this invasive fern, which grows luxuriously from pine flatwood, to hardwood hammock to Cypress strands. All three sites visited at the Big Cypress Reserve are set back from roadways and dirt tracks.

Big Panther Refuge is an old hunting ground. There are remnants of cabins amidst a hardwood hammock of mature oak trees. Sour oranges and grapefruit trees can be found growing in the hammock with dense undergrowth of grasses. Next to the hammocks are pine forests with trees that grow over 60 feet tall, but no Lygodium was found among these pines, unlike the flatwoods at Dupuis and BCSR. As elevation changes on the property, the hammock transitions into a cypress swamp, where pond cypress (Taxodium ascendens) and bald cypress (Taxodium distichum) and saw grass 
(Cladium jamaicense) thrive in water greater than $30 \mathrm{~cm}$ (12inches) deep. Lygodium was observed growing in the interior of a cypress dome, where it was rooted on the roots and decomposing trunks of old cypress and hammock species. Most of the plants were young, single plants independent of a mature vine. There were prothaluses present as well as sporelings that were judged to be a few weeks old. This area had been treated 2 years prior with Rodeo, followed by chopping and burning and manual removal.

\section{MATERIALS AND METHODS}

\section{Plant Materials}

The active growing croziers (fiddleheads) were collected from the three locations in groups of 4 or 5, along with a stem and root support of approximately 6 inches. Plant samples were collected with the soil in which the roots were embedded and placed in shallow elongated containers, capable of supporting root development and stable plant growth. Plants were grown in commercial potting soil, which was watered every three days to maintain the appropriate soil moisture for optimal growth and development. After several weeks, sporelings were transferred to 6 inch pots, 3 to 5 plants per pot. Plants within any one pot were at different growth stages ${ }^{9}$ in order to observe the effect of the inoculum on L. microphyllum at different stages of maturity. The effect of a pathogen on a plant may be significantly different at various growth stages (Shrum 1982). Many plants are most vulnerable when young, but as they become established and more mature, they develop a resistance to some pathogens and extreme environmental conditions.

\footnotetext{
${ }^{9}$ Plants differed in age from 1 week (fiddle head) to 12 weeks old.
} 
Plants were watered during experimental treatment, with water applied directly to the soil to avoid removal of inoculum by excessive washing of leaves.

The number of plants available for the experiments were constrained by high greenhouse temperatures in the summer of 2004 due to a malfunction of one of the cooling fans. Several young plants intended for host specificity experiments were lost Saw palmetto seedlings did not flourish in the greenhouse and could not be used for the study. Cypress plants were not used for the study as their response to treatment became inconclusive due to their approaching the dormancy period. At this stage, browning leaves could not be distinguished from necrotic leaves without microscopic examination of every individual leaf.

\section{Preparation of inoculum}

Dr. Douglas Boyette of the United States Department of Agriculture (USDA) research station in Stoneville, Mississippi provided the fungal isolate of Myrothecium verrucaria used in this study. The fungus was cultured for 4 to 6 weeks at $25^{\circ} \mathrm{C}$ on potato-dextrose agar (PDA) manufactured by Fisher Scientific. Conidia were aseptically transferred from agar plates using moist cotton swabs. Three plates were swabbed and conidia were suspended in $40 \mathrm{ml}$ of sterile water. $10 \mu \mathrm{l}$ of the suspension was pipetted and added to $90 \mu 1$ of sterile water in an eppendorf tube. A $1 \mu 1$ aliquot was then placed on a hemacytometer and counted under a phase microscope to determine the conidial concentration in suspension. Swabbing of several plates and the suspension of conidia were repeated, tubes containing the suspension were centrifuged and the conidial pellets 
combined to produce a stock with conidial concentration ${ }^{10}$ capable of producing suspensions at concentrations of $1 \times 10^{8}$ conidia $/ \mathrm{ml}, 8 \times 10^{7}$ conidia/ml and $4 \times 10^{7}$ conidia/ml. These were the same concentrations used by Yang and Jong (1995a) in experiments on leafy spurge.

Aqueous inoculum suspensions consisted of conidial stock suspension in a $2 \%$ dextrose solution and mixed with Wesson ${ }^{11} 100 \%$ pure vegetable oil in a 9:1 vol/vol ratio modified from Yang and Jong (1995a). Inoculum was poured into spray bottles, which were then shaken to evenly distribute conidia before each application. Other researchers conducting experiments with Myrothecium have used other surfactants such as an invert emulsion used by Yang and Jong (1995a) in their experiment on leafy spurge.

Fungal efficacy and host specificity experiments were conducted in the greenhouse at the Florida International University.

Growth Media Study

The apical growth of a fungus gives it penetrating power by causing hyphal tips to penetrate the cell walls of plants; this feature makes fungi important as plant pathogens, and as the major degraders of wood and other physically hard materials. In order to determine which media was most suitable for the growth of the fungus $M$. verrucaria at a rate suitable for experimental purposes, several growth media were inoculated with a swab of the fungus previously grown on $10 \%$ Potato dextrose agar (PDA). The media

\footnotetext{
${ }^{10} \mathrm{It}$ is easier to dilute a suspension than make it more concentrated; hence final $40 \mathrm{ml}$ stock contained $36 \times 10^{9}$ conidia/ml.

${ }^{11}$ The mention of the brand of oil in this paper in no way guarantees the standard of the product. Similar products may or may not produce the same effect.
} 
investigated included 10\% PDA, full strength PDA, PDA with $10 \%$ glucose, and Nutrient Agar $^{12}$. Growth diameter ${ }^{13}$ was measured and recorded after 3 weeks.

\section{$\underline{\text { Conidial concentration study }}$}

The objective of this experiment was to investigate the effect of two conidial concentrations of $M$. verrucaria on L. microphyllum. A greenhouse inoculation study was set up using composite L. microphyllum plants collected from three different field sites. Treatments consisted of two conidial concentrations $\left(1 \times 10^{7}\right.$ and $1 \times 10^{8}$ conidia per $\mathrm{ml}$ ) and the non-inoculated control. The L. microphyllum plants were grown in 6" plastic pots with fifteen pots for each treatment and 6 plants in each pot. Plants were spray inoculated to runoff with conidial suspension. Control groups were sprayed with $2 \%$ dextrose solution and vegetable oil emulsion without the conidia. Water was applied directly to the soil in the pot to avoid washing inoculum off the leaves. After the first spray inoculation, five more spray inoculations were done at 4-day intervals until day 24. Disease development was evaluated prior to spray inoculation and on days 4,12 , and 24. The number of infected leaves and the severity of infection were recorded for each plant in the study. Average greenhouse temperature during the experiments was $30^{\circ} \mathrm{C}$ with a relative humidity of $90 \%$.

\footnotetext{
${ }^{12}$ General purpose culture medium consisting of peptone, beef extract and agar.

${ }^{13}$ Diameter was taken across three different areas of the circular growth; the three values were averaged and recorded.
} 


\section{$\underline{\text { Host Specificity study }}$}

Because L. microphyllum occupies a wide range of habitats, the number of nontarget species that may be affected by field application is large. I selected native plant species commonly found in habitats in which L. microphyllum is a significant problem in south Florida and some exotics found in close association were also tested. Host range studies were conducted in the greenhouse using two concentrations of $M$. verrucaria: $1 \mathrm{x}$ $10^{7}$ and $1 \times 10^{8}$ conidia per $\mathrm{ml}$. Control plants were sprayed with a mixture of vegetable oil and water on corresponding days. Plants were spray inoculated three times, on days 0 , 4, and 8. Native plants were obtained from the Fairchild Tropical Botanical Garden, Miami Florida. Due to limited availability an unequal number of plants were used under each treatment. The description of the native species and number of plants used under each are presented in the table below. Final observations on the plants were taken 21 days after the first inoculation.

The prospect of $M$. verrucaria as a mycoherbicide is dependent on the percentage of infected plants as well as the severity of the infection. If more than $15 \%$ of plants tested are affected, $M$. verrucaria would not be recommended for use in its current state and the promise of field application would require extensive study to try to eliminate the elements of the fungus that affect the non-target plants while maintaining the efficacy of this fungus on the invasive Lygodium fern. Under the EPA pesticide assessment guidelines, subdivision J- Hazard evaluation; Nontarget plants, vegetative vigor dose response testing should not exceed $25 \%$ of population tested. 
Table 1. Name and number of plants used in the host range study

\begin{tabular}{|c|c|c|c|c|}
\hline \multicolumn{2}{|c|}{ Plant species tested } & \multicolumn{3}{|c|}{$\begin{array}{c}\text { Number of plants tested } \\
\text { Conidial concentration of } \\
\text { treatments }\end{array}$} \\
\hline Common name & Scientific name & $1 \times 10^{7} \mathrm{ml}^{-1}$ & $\begin{array}{c}1 \times 10^{8} \\
\mathrm{ml}^{-1}\end{array}$ & Control \\
\hline $\begin{array}{l}\text { Everglades } \\
\text { palm }\end{array}$ & $\begin{array}{l}\text { Acoelorraphe } \\
\text { wrighhtii }\end{array}$ & 25 & 19 & 3 \\
\hline Slash pine & Pinus elliottii & 12 & 9 & 3 \\
\hline glauca & Simaruba glauca & 59 & 24 & 4 \\
\hline Sawgrass & $\begin{array}{l}\text { Cladium jamaicense } \\
\text { Chrysalidocarpus }\end{array}$ & 95 & 34 & 5 \\
\hline Areca palm & lutescens & 147 & 64 & 5 \\
\hline $\begin{array}{l}\text { Silver thatch } \\
\text { palm }\end{array}$ & $\begin{array}{l}\text { Coccothrinax } \\
\text { augentata }\end{array}$ & 108 & 37 & 5 \\
\hline Brassica juncea & Brassica junecea & 64 & 28 & 5 \\
\hline Dollarweed & Hydrilla boariensis & 63 & 37 & 5 \\
\hline Bahia grass & Paspalum notatum & 53 & 31 & 5 \\
\hline
\end{tabular}

While the desired rate and severity of infection of Lygodium is greater than a rating of 2 , the effect desired in non-target or native plants is less than 2 . The average rating of disease infection of native plants will definitely be a strong factor in the recommendation of $M$. verrucaria as an applicable and effective control for $L$. microphyllum in South Florida.

Growth Chamber study

To investigate the effects of key environmental parameters on the responses of $L$. microphyllum to $M$. verrucaria, a series of growth chamber studies were conducted. 
These experiments involved different combinations of humidity and temperature within a growth chamber. Temperatures tested were $30^{\circ} \mathrm{C}\left(\mathrm{T}_{1}\right)$ and $22^{\circ} \mathrm{C}\left(\mathrm{T}_{2}\right)$ with relative humidity values being $90 \%\left(\mathrm{H}_{1}\right)$ and $40 \%\left(\mathrm{H}_{2}\right)$. Plants were watered for 30 minutes each morning and 15 minutes each afternoon by aerial sprinklers. Light was maintained at 12 hours of darkness with a light setting of 2 . Growth chamber studies were conducted at the USDA, ARS facility located in Old Cutler 'Miami'. The four combinations were: $\left(T_{1}\right)$ $\left(\mathrm{H}_{2}\right),\left(\mathrm{T}_{2}\right)\left(\mathrm{H}_{1}\right),\left(\mathrm{T}_{2}\right)\left(\mathrm{H}_{2}\right)$ and $\left(\mathrm{H}_{1}\right)\left(\mathrm{T}_{1}\right)$. Results from these experiments were visually compared to plants that were treated within a room with temperature and humidity settings at $18{ }^{\circ} \mathrm{C}$ and $50 \%$ respectively. The latter group was not included in the statistical analyses.

Silwet L-77 (an organosilicone surfactant) was used in this study after a preliminary study demonstrated that it caused an increase in the efficacy of $M$. verrucaria on L. microphyllum.

\section{Measurements and Statistical analysis}

To measure the pathogenicity of $M$. verrucaria on $L$. microphyllum and $L$. japonicum the disease rating/ index used by Yang and Jong (1995b) was followed. Disease severity was rated on each of the 4 day intervals before inoculation using a 0 to 4 rating scale to indicate disease severity: $0=$ no infection, no lesions on leaves; $1=$ tip of leaves curled, brown, or less than 10 spots, not coalesced on a leaf; $2=$ more than 10 spots on a leaf, spots on leaf coalesced. Some leaves yellow or brown, or lower leaves dropped but plant top still green; 3 = plant top brown or killed with leaves turned down or stems defoliated but lower portions of stems still green; $4=$ Whole plants dying or dead. 
A disease index (DI) score was calculated as (summation of [severity rating $\mathrm{x}$ number of plants in that class) / total number of plants (Yang and Jong 1995a). DI below 3.0 indicated slight-to-moderate infection (resistant), but at or above 3.0 indicated severe infection (susceptible). This DI score was used in the conidial concentration and host specificity studies to determine the overall effect of $M$. verrucaria on plants being tested.

The SPSS statistical software package version 13.0 (SPSS Inc. $233 \mathrm{~S}$. Wacker Dr. Chicago, Illinois) was used to run ANOVAs, MANOVAs Chi square, F and t- tests used in analyzing the data. Non-parametric statistical analyses were used to assess most of the data presented here. In SPSS, categories were converted into ranked values with value labels. On examining the tests of within subject effects, sphericity was assumed and was significant and the Greenhouse-Geisser corrected model was used. Pairwise comparisons were used to compare differences across treatment groups on observed days as well as differences in observed days for each treatment. In investigating the final effects of conidial concentration on native plants, Pearson Chi-square tests were conducted. Where groups were small, end point analyses were pooled to better illustrate and compare responses of control and treatment groups. Growth Chamber study analyses involved a series of ANOVAs and Pairwise comparisons.

\section{RESULTS}

Growth media study

As illustrated in figure $3,100 \%$ PDA was the most fruitful in producing new fungal growth over the 3-week period, with the average diameter of dense fungal cover 
being just over $5.5 \mathrm{~cm} .100 \%$ PDA with added glucose did not differ much, with average fungal growth diameter being $5.24 \mathrm{~cm}$.

Figure 3. Bar chart illustrating the comparative growth of $M$. verrucaria on different growth media.

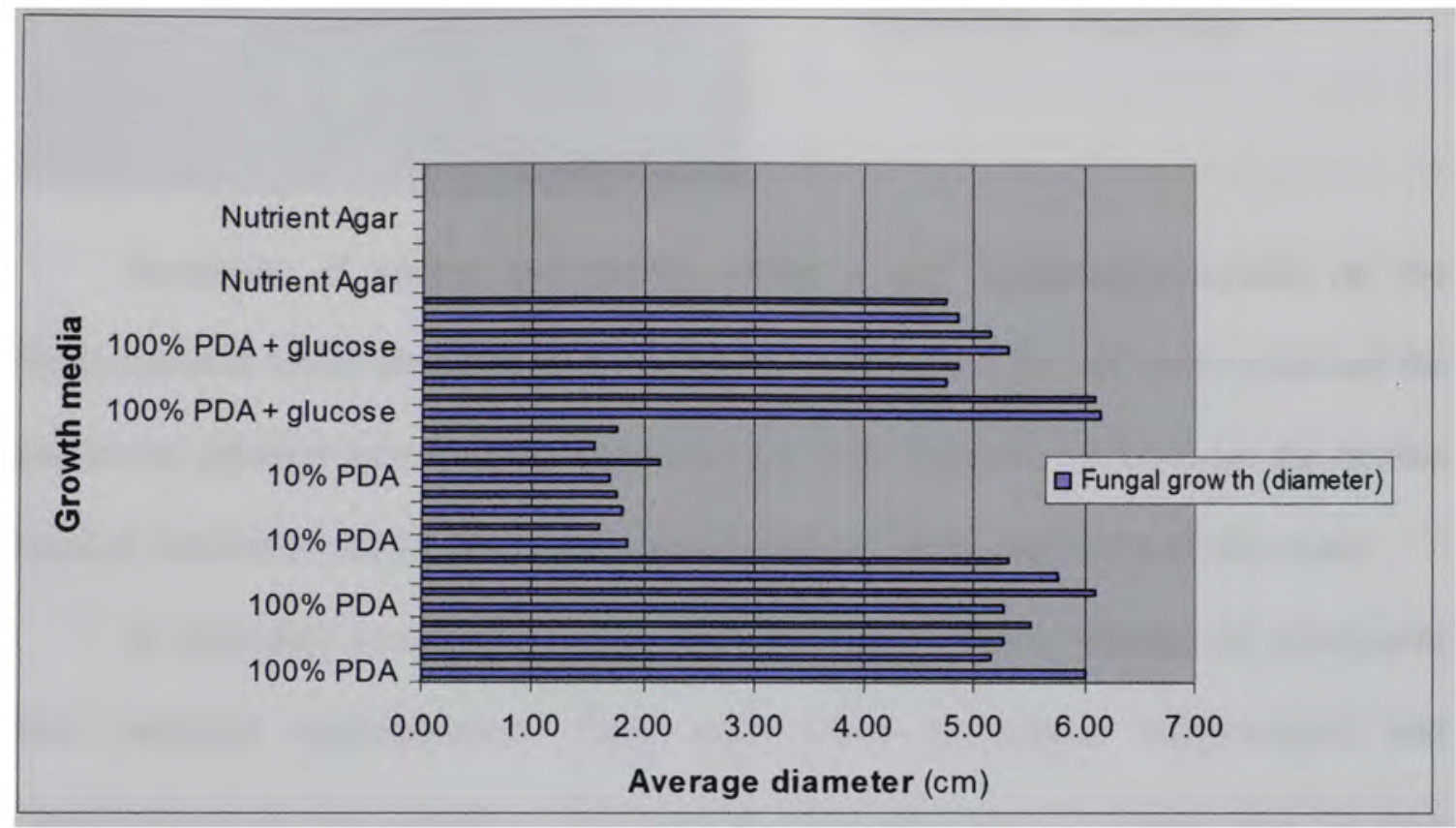

The $10 \%$ PDA produced a sparsely covered surface with the average diameter being $1.77 \mathrm{~cm}$ and the circumference of growth not far beyond the point of inoculation. The nutrient agar yielded no $M$. verrucaria growth; we can conclude that it does not include a mixture of nutrients favorable to the growth of $M$ verrucaria. The fungus was grown on $100 \%$ PDA for the remainder of the study. As seen in figure 4 overleaf, $M$. verrucaria produces dark green spores when grown on PDA, close observation under the microscope yields the elongated shape of these spores as well as the green yet somewhat transparent coloration. 


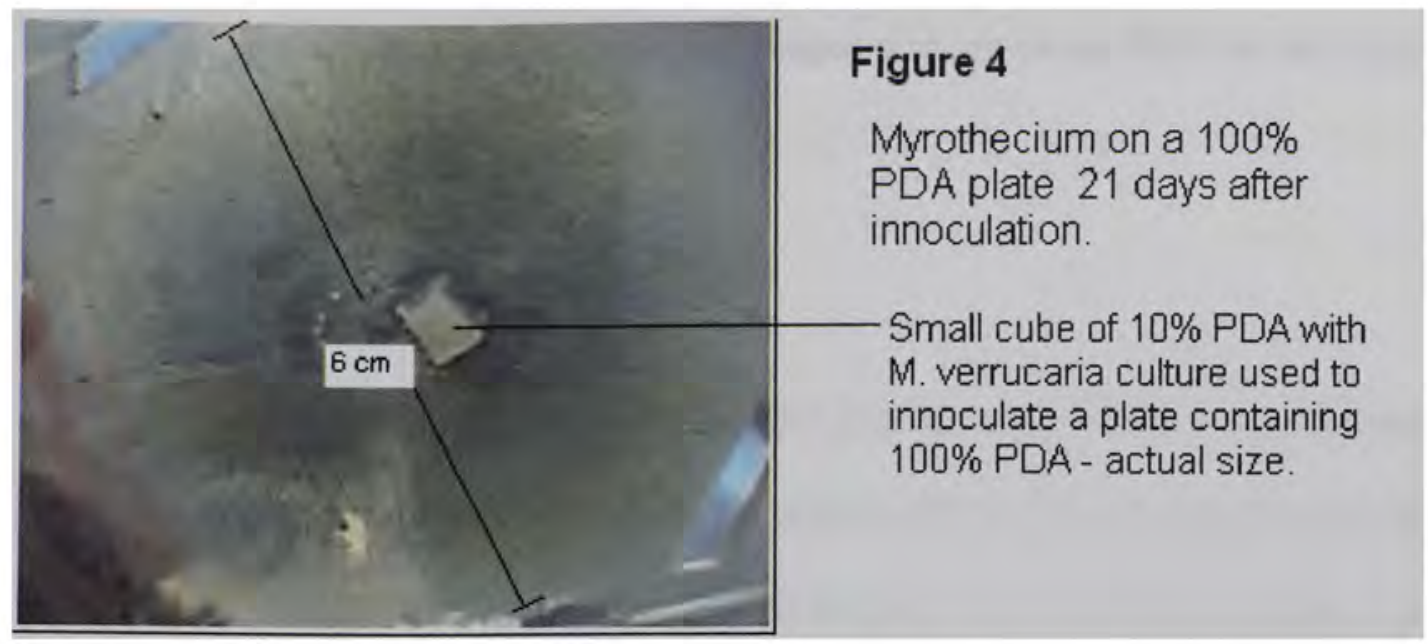

Hundreds of spores are visible within a $\mathrm{cm}^{3}$ area when viewed on the hemacytometer under the microscope. The number of spores per $\mathrm{cm}^{3}$ is recorded and the suspension adjusted appropriately and combined with vegetable oil to obtain the desired conidial concentrations for the experiments carried out in the remainder of this study.

A secondary media study arose with the need to isolate tainted $M$. verrucaria from bacterial contamination. Two wide range antibiotics; Streptomycin and Chloramphenicol were added to two different PDA solutions for plating, and the pink marine agar was used to culture $M$. verrucaria, as it is more resistant to bacteria than regular PDA. The growth of Myrothecium on Marine agar plates was slow and was white in its initial stages after which the common dark green coloration became apparent. While the growth on PDA is powdery in appearance ${ }^{14}$, on the marine agar, $M$. verrucaria grew into the surface of the agar and was pasty in appearance. It was more difficult to remove a sample of the fungus from the marine agar than from PDA, after performing several serial dilutions and consequent platings the attempt at isolating $M$. verrucaria from

\footnotetext{
${ }^{14}$ The growth on PDA resembles that of an ascomycete (powdery mildew fungus)
} 
bacterial contamination was successful and fungus was grown on PDA for the remainder of the study.

\section{Conidial concentration study}

The number of infected leaves and the severity of infection were recorded for each plant in the study. Results from the greenhouse inoculation experiment showed that the extent of disease development on L. microphyllum by $M$. verrucaria varied greatly with the inoculum concentration (Fig.5). Following inoculation there was a steady increase in the number and size of necrotic spots, in both low and high conidial concentration treatments. The L. microphyllum plants inoculated with $1 \times 10^{8}$ conidia per $\mathrm{ml}$ showed higher average number of leaf infections compared to the $1 \times 10^{7}$ conidia per $\mathrm{ml}$ inoculated plants and the differences were significant $(\mathrm{p}<0.05)$ at the end of the experiment. The necrotic spots on the leaves following $M$. verrucaria conidial infections increased in size over time and coalesced, resulting in symptoms becoming visibly more severe (Appendix I and II). Leaf infection seemed to be more prominent on the upper fronds and upper region of the vine. Observation of plants 21-24 days after the initial inoculation showed that those in the higher concentration group had infection spreading throughout the entire plant. Some necrosis was observed on leaves of newly expanded stems, but upcoming croziers showed no signs of infection. Necrotic spots were prominent along the leaf edge rather than in the center, and the color of the infected area ranged from a yellowish brown to dark brown.

The number of leaves infected per plant per treatment did not show a marked increase between day 4 and day 10, however the amount of necrotic spots that coalesced 
increased in number (Fig. 6). As the infected area increased on the leaf surface the effect of the fungus spread to adjacent leaves and by day 21 the number of infected leaves had doubled and infection was visibly more severe. Plants maintained this pattern through to day 24 of study. Leaf infection seemed to be more prominent on the upper region of the vine. There was some necrosis observed on leaves of new growth stems but emerging croziers showed no signs of infection.

Figure 5. The effect of varying conidial concentrations of Myrothecium verrucaria on disease development (average number of infected leaves/plant) in Lygodium microphyllum.

b The mean difference is significant at $\mathrm{p}=0.05$.

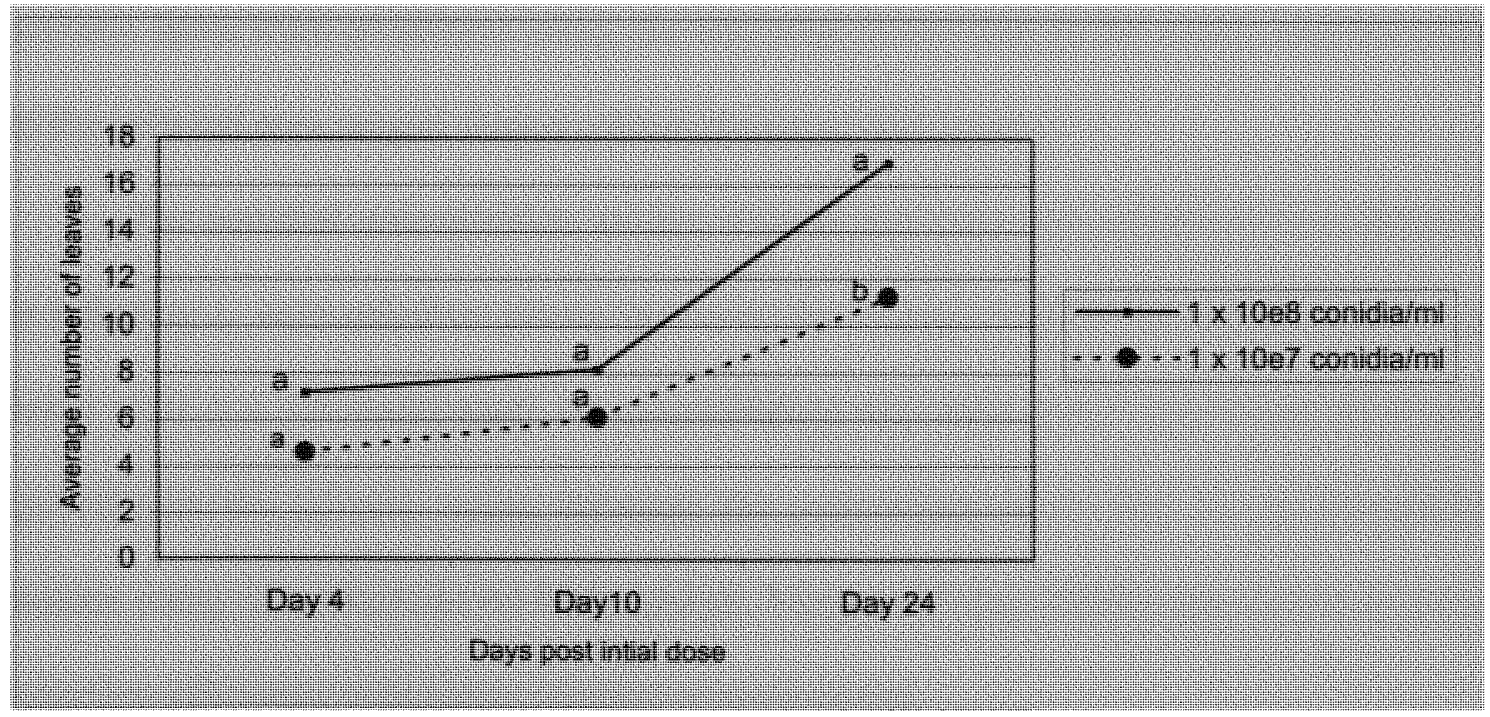

When the two levels of $M$. verrucaria conidial inoculum concentrations were compared at the end of the study, there was no significant difference in the number of 
plants infected however, the extent of infection showed a significant difference, seen in the rate and severity of the infections. The first sign of infection was visible $48 \mathrm{hrs}$ post inoculation and by day $4,28 \%$ of the plants in both conidial inoculation treatments were infected with similar DIs. On day 12 infection was visible on all plants in the higher conidial concentration group and by day 16 all of the plants $(100 \%)$ demonstrated some degree of infection. Plants dosed with the higher conidial concentration displayed more brown necrotic spots on leaves and had a much higher infection of leaf area. The DI between treatments was significantly different after day 4 and the progression of the disease showed a marked difference between conidial concentrations. This difference became more visible as the disease progressed. A pairwise comparison of daily response to treatment across groups showed significant differences $(\mathrm{p}<0.05)$ for each conidial treatment. No disease symptoms were detected on control plants while on infected plants necrotic spots were prominent along the leaf edge rather than in the center, and the color of the infected area ranged from a yellow brown to dark brown.

The conidial concentration studies showed that both concentrations were effective in infecting L. microphyllum plants; however, the average number of infected leaves was lower with $1 \times 10^{7}$ conidia per $\mathrm{ml}$ concentration and there was a significant difference $(p<0.01)$ in the severity rating between the concentrations on day 12 . In inoculation studies using M. verrucaria on leafy spurge, Yang and Jong (1995b) also observed lower infection efficiency with lower conidial concentrations. 
Figure 6. Infection efficiency of Myrothecium verrucaria conidial concentrations on Lygodium microphyllum. ${ }^{b}$ The mean difference is significant at $\mathrm{p}=0.05$.

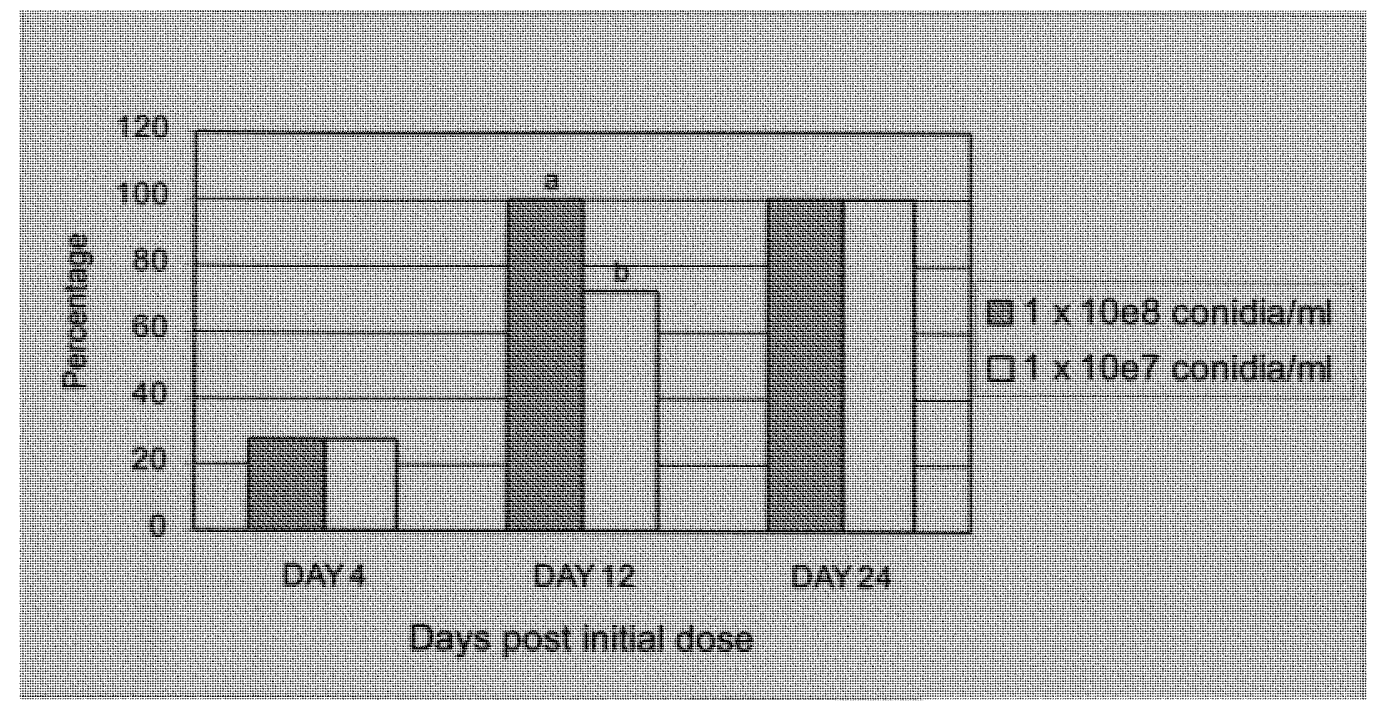

The initial conidial application had very little effect on the fronds but as applications continued more necrosis was observed on some leaves. The necrosis on the surface area of individual fronds also increased over time. In treatments receiving the $1 \mathrm{x}$ $10^{8}$ per ml conidia concentration, plants showed accelerated necrosis of the leaf surface and were the first to exhibit necrosis on entire leaves. By day 21 the DI was approximately 3 (Fig.7), indicating severe infection. Further observations revealed that though the plants didn't lose any fronds, some plants in both groups were entirely necrotic with leaves yellowish-brown to dark brown in color. This is the first report of pathogenicity of $M$. verrucaria on L. microphyllum. 
Figure 7. Disease indices of Lygodium microphyllum inoculated with two concentrations of Myrothecium verrucaria. ${ }^{b}$ The mean difference is significant at $p=$ 0.01 .

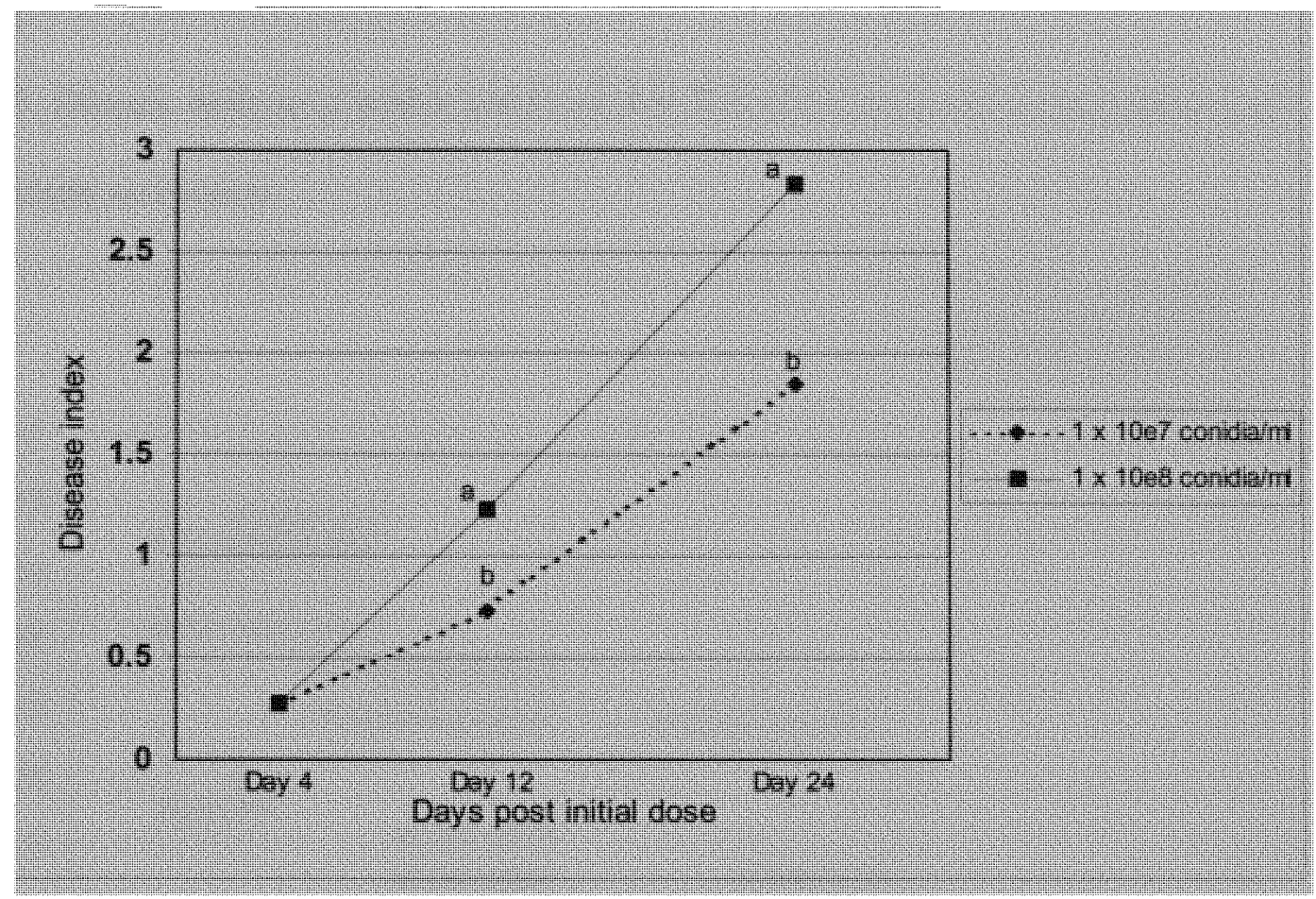

\section{$\underline{\text { Host specificity study }}$}

Native plant species had varying levels of susceptibility to $M$. verrucaria infection, but the symptoms were not severe on any of them (Fig 8). The over all DIs among all of the species tested were very low (DI below 1.0, with the Slash pine showing the highest DI 0.4) indicating mostly resistance according to the DI scale. The DI for Slash pine and Brassica sp. showed that they responded strongly to the conidial concentration treatments, Slash pine and Brassica sp. plants had a higher DI value at $1 \times 10^{8}$ conidia per 
$\mathrm{ml}$ compared to the $1 \times 10^{7}$ conidia per $\mathrm{ml}$ treatment. The non-native Areca palm (Chrysalidocarpus lutescens), Silver thatch palm (Coccothrinax augentata) and Bahia grass (Paspalum notatum) were least affected by $M$. verrucaria; all three plant species showed very little spotting or necrosis following spray inoculation.

Figure 8. Disease indices of native plant species inoculated with two concentrations of Myrothecium verrucaria.

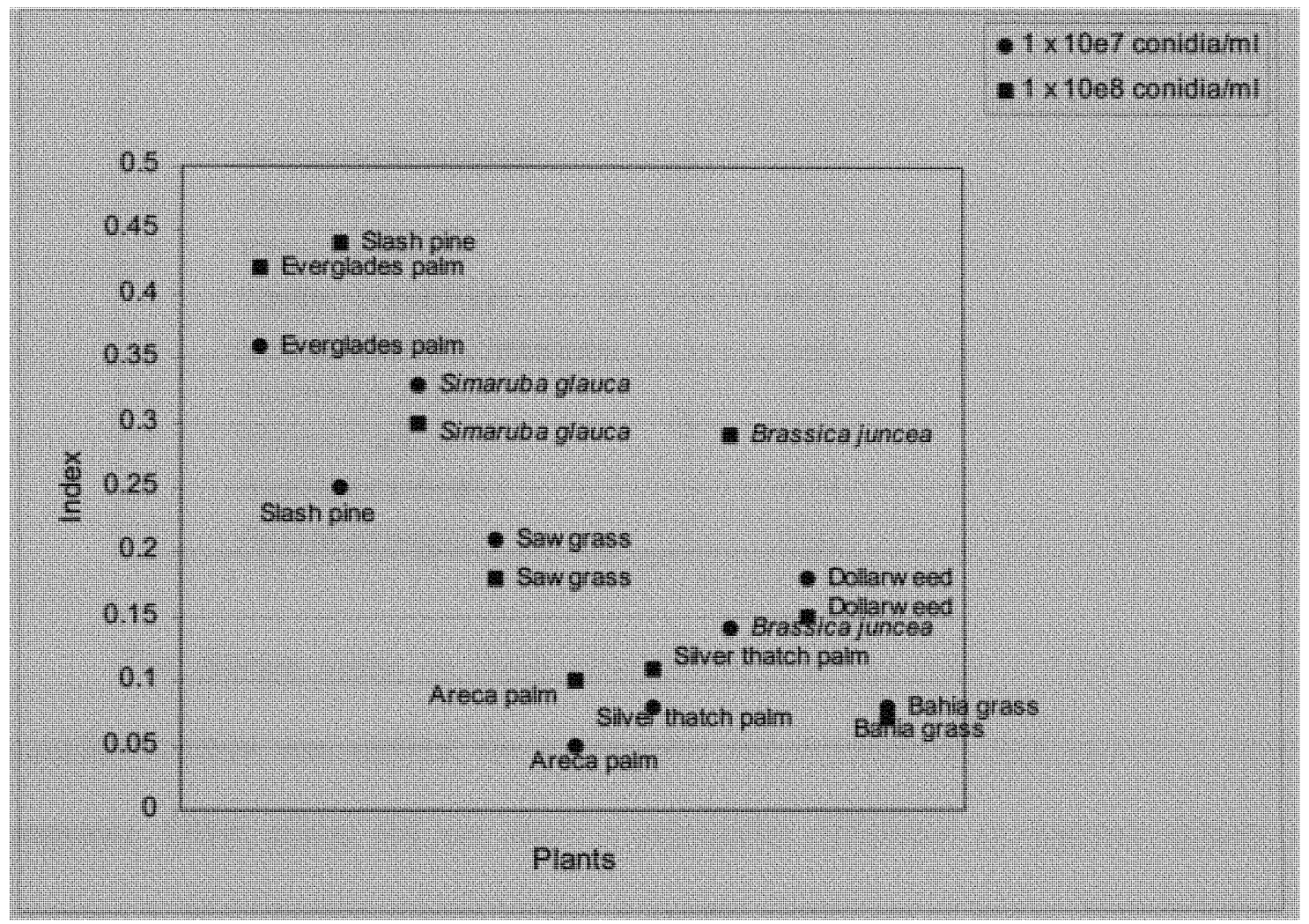

Along with the Everglades palm, Simaruba glauca showed a high rate of infection from both concentrations of $M$. verrucaria used in host specificity studies. Slash pine and Brassica sp. however showed a distinct difference in effect between concentrations. Saw 
grass and Dollar weed are fairly consistent in their resistance to the fungus despite the varying conidial concentration. The non-native Areca palm, Silver thatch palm and native grass used in this study were the least affected by $M$. verrucaria, exhibiting very little spotting or necrosis on their leaves. The table below gives the exact indices for comparison of plant response to $M$. verrucaria.

Table 2. Host specificity disease indices

\begin{tabular}{|ll|c|c|}
\hline \multirow{2}{*}{ Plants tested } & \multicolumn{2}{|c|}{ Conidial conc. of M. verrucaria } \\
\cline { 3 - 4 } 1 & Acoelorraphe wrighhtii & $1 \times 10^{7}$ conidia/ml & $1 \times 10^{8}$ conidia/ml \\
2 & Pinus elliotti & 0.36 & 0.42 \\
3 & Simaruba glauca & 0.25 & 0.44 \\
4 & Cladium jamaicense & 0.33 & 0.30 \\
5 & Chrysalidocarpus lutescens & 0.21 & 0.18 \\
6 & Coccothrinax alta & 0.05 & 0.10 \\
7 & Brassica juncea & 0.08 & 0.11 \\
8 & Hydrilla boariensis & 0.14 & 0.29 \\
9 & Paspalum notatum & 0.18 & 0.15 \\
\hline
\end{tabular}

The disease index in Slash pine almost doubled when a more concentrated conidial solution was applied, the Areca palm and Brassica sp. both showed a similar response. Other plants did not show a substantial difference in response despite an increase in Myrothecium concentration. A greater percentage of leaves showed infection within a shorter period of time in the intermediate efficacy study, supporting Boyette et al.'s (1999) findings that there is a greater potential for enhancing the infectivity and severity of $M$. verrucaria on L. microphyllum in one single spray inoculation by using the surfactant Silwet L-77. 
The comparison between the effects of varied combinations of temperature and humidity on the $M$. verrucaria - L. microphyllum interactions yielded positive results. There was a significant three-way interaction between days, temperature and humidity. As the days post inoculation increased, there was an observed increase in necrosis on $L$. microphyllum and the necrosis increased with an increase in humidity. Post-hoc tests for pairwise comparisons were conducted using Fisher's LSD test at the $5 \%$ significance level. The post-hoc tests determined that at $90 \%$ humidity there were significant differences in severity between the two temperatures on all three days, with the higher temperature producing a higher severity rating. At $40 \%$ humidity, there was a significant difference in severity between the two temperatures on Day 7 , with the higher temperature producing a higher severity rating. There was no significant difference at days 3 or 10 (Appendix IX $-\mathrm{X}$ ).

Post -hoc analysis within temperature treatments indicated that at both $70^{\circ} \mathrm{F}$ and $80^{\circ} \mathrm{F}$, there was a significant difference in severity rating between the two humidity points at days 3,7 and 10 , with $90 \%$ humidity producing a higher severity rating. At both $80^{\circ} \mathrm{F}$ and $90 \%$, the severity of infection showed a significant increase with time, the highest rating being recorded on day 10 . A similar response was observed at $80^{\circ} \mathrm{F}-40 \%$ humidity, $70^{\circ} \mathrm{F}-90 \%$ humidity and $70^{\circ} \mathrm{F}-40 \%$ humidity (Appendix XI - XII).

The difference in means is higher at the lower temperature level but the mean severity rating is higher at the higher temperature level; this data demonstrates that at a high temperature - high humidity combination, the effect of $M$. verrucaria on $L$. microphyllum is greatest with a faster rate of infection than is observed at the lower 
temperature combinations between the three days examined. Except on day 3 in the $40 \%$ relative humidity bracket, there was a significant difference between time post inoculation and both temperature levels (Table 3.)

Table 3. Comparison of Disease indices of Plants under varied temperature and humidity parameters in the growth chamber.

\begin{tabular}{|l|c|c|c|}
\hline Humidity & Day & \multicolumn{2}{|c|}{ Temperature } \\
& & $22^{\circ} \mathrm{C} / 70^{\circ} \mathrm{F}$ & $30^{\circ} \mathrm{C} / 80^{\circ} \mathrm{F}$ \\
\hline $40 \%$ & 3 & 0.5 & 0.69 \\
& 7 & 1.02 & 1.28 \\
& 10 & 1.61 & 1.76 \\
& & & \\
$90 \%$ & 3 & 0.78 & 2.87 \\
& 7 & 1.52 & 3.28 \\
& 10 & 2.07 & 3.61 \\
\hline
\end{tabular}

To confirm Myrothecium induced necrosis, samples of leaves from treated plants used in all experiments were examined under a light microscope with an Abbe ${ }^{15}$ condenser as well as a stereo microscope (Appendix XV). The hyphal growth of the fungus was compared to control leaves treated with Myrothecium verrucaria and stored aseptically. The observed effects are valid under the specified experimental conditions and may differ to some degree should field tests be done.

${ }^{15}$ Light focusing system under the stage. 


\section{DISCUSSION}

The growth of L. microphyllum continues to be a significant problem in South Florida since this recipient community offers different environmental conditions from its native region (Maron et al. 2004) and lacks any pests that would usually control its growth in such regions. As the fern invades several ecosystems a variety of plant populations are at risk of being out-competed and replaced by this aggressive weed. It is decidedly difficult to separate the vines from native plants for treatment especially since many areas of invasion are very large or are not easily accessible by ground.

The conidial concentration studies illustrated that both test treatments had an effect on L. microphyllum plants. Concentrations show similar effects to those observed when used by Yang and Jong (1995a) in experiments on leafy spurge. The initial application showed no apparent effect on the fronds but as applications continued necrosis was observed on some leaves. The necrosis on the surface area of individual fronds also increased over time. The rate of infection correlates with the concentration of the mycoherbicide solution; the higher concentration $\left(1 \times 10^{8} / \mathrm{ml}\right)$ showed a greater rate of necrosis on the surface area of the leaves, and plants in this treatment were the first to lose entire leaves to brown necrotic spots. Observation of the plants post study revealed that several plants dosed with the highest conidial concentration lost all exposed leaves to necrosis however new croziers were seen growing within the pots. These crosiers developed into vines which seemed unaffected by the fungus that had been applied to the previous plants.

Native plant species showed a favorable response to Myrothecium applications, of the 909 plants tested, less than $5 \%$ were affected severely and it was also observed that 
the lag time for development of infection was longer compared to L. microphyllum (data not shown). While L. microphyllum showed symptoms of infection within 48 hrs of dosing, the plants tested in the host specificity study did not show any visible effects until 9 days post initial dose. There was very little indication that necrosis would progress to a severity rating of 3 as the infected plants showed only a few spots on only a few leaves, The Everglades palm, Areca palm, Saw grass and Bahia grass tested did not show any symptoms until day 17 post initial dose, with very limited necrosis. None of the native plants displayed extensive necrosis and there was no secondary spread of the pathogen to uninoculated neighboring plants. The results suggest that there is potential for using $M$. verrucaria as a biological control in the field as it does not seem to have a significant negative effect on the native species tested. Other toxicity tests of this fungus have proven negative on some invertebrates (Warrior et al.1999), supporting its use as a bioherbicide.

The optimum time for treating Lygodium infested areas would be during the summer months when the fern growth is luxurious as this would ensure a greater inoculation surface. The growth chamber studies indicate that summer temperatures and humidity are favorable for infection by the Myrothecium pathogen. If treatments were performed during the low temperature and humidity of the winter months, a reduction in Lygodium coverage would expose a greater amount of non-target plants to direct inoculum dosing and there would be a lower amount of target plant foliage exposed for infection. The use of a surfactant increases the efficacy of $M$. verrucaria by reducing the rate of evaporation under low relative humidity. The influence of the surfactant also provides greater efficacy during high temperature - high humidity conditions. To confirm 
that the visible necrosis was as a direct result of $M$. verrucaria, several leaves were examined post study and fungal cultures were assessed; $M$. verrucaria was positively identified in all samples. Croziers that germinated post inoculation did not show the presence of $M$. verrucaria.

Results are preliminary since only a very small representative portion of the plant species present in south Florida was tested during this study and there is no guarantee that some native plants won't be more severely affected. Broader more long-term host specific studies must be carried out on other plant species, as well as insects and mammals before we can safely say whether or not this strain of $M$. verrucaria has a significant prospect of being approved for use in the field. The successful control of $L$. microphyllum may be dependent on a combination of control methods, which may prove to be more successful than any one on its own. A reduction in the size of pest plant populations, decrease in growth rate or ability to reproduce as well as reduction in vigor may measure success with regards to Lygodium.

As a general plant pathogen $M$. verrucaria possess certain advantageous features making it a potentially useful mycoherbicide; the infective propagules of $M$. verrucaria, conidia can easily be produced in high concentrations; Since M. verrucaria is a weak competitor (Grosu and Hulea, 1973; Domsch et al. 1980), possibilities for disturbances in native soil microbial population following spray inoculation are probably very low. Even though direct inoculation with $M$. verrucaria results in severe injury and damage to the plant tissue, the infection is not systemic and does not spread from diseased plants to healthy plants. Under natural conditions conidial concentration and dew temperatures limit the pathogenicity of $M$. verrucaria. 
Zidack et al., 1992 reasoned that the use of an adjuvant ${ }^{16}$ would lead to an increase in the virility of the Myrothecium pathogen and that the pathogenic effect exhibited on non-target plants would be increased. The second phase of experiments involving the adjuvant Silwet-77 demonstrated increased virility but the experiments did not involve non-target plants. There is a concern regarding mycotoxins such as macrocyclic trichothecenes that are produced in culture by M. verrucaria (Mortimer et al. 1971; Walker and Tilley 1997). To date, evidence for presence of mycotoxins in infected plants is lacking; analysis of extracts from M. verrucaria spray inoculated kudzu, soybean (Glycine max), and sicklepod (Cassia obtusifoloa) showed that there were no trichothecene compounds present in the infected plant tissue (Kuti et al., 1987, Beckwith and Dangerfeild, 1996, and Abbas et al., 2001). Further it was observed that the chloroform-methanol extracts of kudzu leaves and stems treated with $M$. verrucaria spores were less cytotoxic to four cultured mammalian cell lines than the corresponding extracts from control plants (Abbas et al., 2001).

The growth of Lygodium in the native environment is so extensive that any spray application whether by ground or air would result in very little of the inoculum coming in contact with native plants. Possible contact may arise as wind blows droplets onto native plants but the amount of the inoculum reaching these plants would not be sufficient to cause irreversible damage. $M$. verrucaria is a saprophytic fungi and is a weak pathogen at most, there has been no indication throughout these greenhouse studies that conidia will spread to neighboring plants, as no untreated plants in close proximity were affected. The

\footnotetext{
${ }^{16}$ An agent which modifies the effect of other agents while having few if any direct effects when given by itself - Wikipedia
} 
conidial concentration necessary to be deemed detrimental does not occur naturally and stray droplets pose no threat of establishing native colonies and thriving in an introduced environment.

Lygodium has resulted in reduced establishment of native tree and shrub seedlings, reduction in the amount of space, water, sunlight and nutrients that would normally be available to native species in the cypress stands and tree islands of $S$. Florida. It has altered fire regimes in scrub ecosystems and is encroaching on the pine and scrub oak habitat. A plan to eliminate this highly invasive vine would prove beneficial to S. Florida's delicate ecosystem.

\section{CONCLUSION}

It is difficult to predict the habitat range an invasive plant based on information from its native range, and the areas of infestation in a new environment may present factors not typical of the native region. As such it is often prudent to curb or eliminate a problematic plant before the task to control it and the superficial damage done is too great. In Florida the effect of Lygodium was noticeable when large areas of native plant communities were severely overshadowed by the fern. The first attempt at control was to physically remove the vines, but this labor-intensive approach requires much manpower and energy and as mentioned by Gardener (1993), such efforts have frequently proven unsuccessful for established invasive species covering extensive areas of land. In the case of Lygodium, removal of the fern by cutting, spraying and then bagging the remains did not lead to any permanent significant reduction in cover in the applied areas; there is also concern for loose spores forming gametophytes which reproduce, germinate and replace 
old vines. The reduction and eventual eradication of Lygodium from S. Florida will rely on a concerted effort of management practices that are self-perpetuating.

Invasive plants are good candidates for biological control if they have a narrow taxonomic range, L. microphyllum has only one closely related native species in Florida, hence biological control should be an acceptable approach to curbing and eliminating this unwanted fern (Pemberton, 2002). It is however very important to select a biological control that demonstrates little to no prospects of uncontrolled spread or significant effects on non-target organisms.

The importance of an effective biocontrol for this very problematic fern is emphasized by its rapid rate of growth in both disturbed and undisturbed native habitats. At the same time, it is important to find a control that will curb the growth and spread of this invasive without posing a threat to the environment. Lygodium has disrupted the ecology and natural ecosystem in some areas of S. Florida, thereby posing the threat of displacing some plant and animal species. Over the last two years L. microphyllum has almost doubled its cover along the Kitchen and Wilson creek trails at the Jonathan Dickenson State park (personal observation). It can be seen along the creeks and bridges, covering ferns, marsh grasses and climbing the tall trunks of pine trees set back from the foot path. Along interstate 95 and the Florida turnpike north of exit 116 (Indiantown Road) one can find small patches of the fern growing up pine trees, over fences and shrubs along the road way. Given the seriousness of the infestation problem, any biological control method which can effectively hinder the fern's growth and spread without significant non-target effects will be a valuable tool in the overall integrated management strategy. 
To avoid or minimize the effects on native species it is important to develop a $L$. microphyllum specific native pathogen as a biological control agent. Currently we are in the process of testing some of the native pathogens that were isolated from the diseased fronds of L. microphyllum. Given the seriousness of the infestation problem, any biological control method which can effectively hinder the fern's growth and spread without significant non-target effects will be a valuable tool in an overall integrated management strategy (Charudattan, 2001). Further studies are needed concerning the development of $M$. verrucaria as a mycoherbicide to control L. microphyllum. 


\section{Literature Cited}

Abbas, H. K., H. Tak, C.D.Boyette, W.T. Shier, and B.B. Jarvis. 2001.

Absence of macrocyclic trichothecenes from kudzu (Pueraria montana) plants treated with a high producing isolate of Myrothecium verrucaria. Phytochem. 58: 269-276.

Arnold, D. 1999. Molecular Variability of Fungal Pathogens. Plant Pathology 48 (4): 566

Barratt, B.I.P., C.M. Ferguson, S.L. Golson, C.M. Phillips and D.J. Hannah. 2000. Predicting the risk from biological control agent introductions; A New Zealand approach. Pp. 59-75. In P.A. Follett and J.J. Duan (eds.) Nontarget effects of biological control. Kluwer Academic Publishers. Boston, Massachusetts.

Beckwith, J.R. and C.W. Dangerfield, 1996. Forest resources one-lines. Extn. For. Res. Unit, Bull. For., 96-040, Georgia Coop. Extn. Serv., Univ. GA Press, Athens, GA.

Bergman, F., B. Yagen and B.B. Jarvis. 1992. The toxicity of Macocyclic trichothecenes administered directly into the rat brain. Toxicon. 30:10 pp. 1291-1294.

Blackwood, B. 1935. Both sides of the Buka passage. Oxford, Clarendon Press.

Blossey, B. and R. Nöltzold.1995. Evolution of increased competitive ability in invasive Nonindigenous plants: a hypothesis. Journal of Ecology 83: 887-889

Bossard CC and M Rejmanek (1994) Herbivory, growth, seed production, and resprouting of an exotic invasive shrub Cytisus scoparius. Biol Conservation 67:193-200.

Bowers, R.C. 1982. Commercialization of microbial biological control agents. Pp 157173 In Biological control of weeds with plant pathogens. R. Charudattan and H. L. Walker (ed.) John Wiley and sons. New York

Boyette, C.D., H.L.Walker, and H.K. Abbas. 1999. Biological control of kudzu (Pueraria montana) with an endemic fungal pathogen. Proc. South. Weed Sci. Soc. 52 (1999), p. 237.

Boyette, C. D., H. K. Abbas, and H. L. Walker. 2000. Bioherbicidal control of kudzu with Myrothecium verrucaria. Phytopathology 90: S9.

Cairns, J. Jr., B. R. Niederlehner, and E. P. Smith (1995): Ecosystem effects: functional end points. Pp. 1125. In G. M. Rand (ed.) Fundamentals of aquatic toxicology. Effects, environmental fate and risk assessment. Taylor and Francis. Washington D.C. 
Charudattan, R.1982. Regulation of microbial weed control agents. Pp.175-188

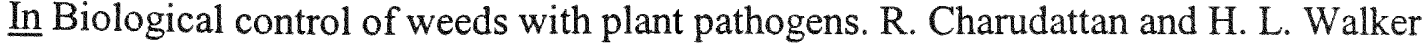
(ed.) John Wiley and sons. New York.

Charudattan, R.2001. Biological control of weeds by means of plant pathogens:

Significance for integrated weed management in modern agro-ecology. BioControl $46: 229-260$

Croft, J. Ferns and Man in New Guinea. Australian National Herbarium Centre for Plant Biodiversity Research.

Dalrymple, G.H. et al 2003. Plant colonization after complete and partial removal of disturbed soils for wetland restoration of former agricultural fields in Everglades National Park. The Society of Wetland Scientists. 23:4 pp. 1015-1029

Domsch, K.H., W.Gams, and T. H. Anderson. 1980. Myrothecium. In Compendium of soil fungi. Vol. 1.pp. 481-487. Academic Press, New York.

Ehler, L.E. 1990. Introduction strategies in biological control of insects.

Pp. 111-134. In M. Mavkauer, L.E. Ehler, and J. Roland, eds. Critical issues in biological control. Intercept. Andover, Haunts, U.K.

Press, San Diego.

Ehler, L.E. 1998. Conservation biological control: past, present and future.

Pp. 1-8. In P. Barbosa (ed.) Conservation biological control. Academic Press, San Diego.

Elton, C. S. 1958. The Ecology of Invasions by Animals and Plants. Methuen, London, UK.

Environmental Growth Chambers, lighting radiation conversions. http://www.egc.com/illumination.html

Evans, H.C. 1992. Pathogen-weed relationships: the practice and problems of host range screening. Abstracts, VIII International Symposium on Biological Control of Weeds, Canterbury, New Zealand, February, 1992, p.62.

EXTOXNET. 1996. Garlon. Pesticide Information Profiles. Extension Toxicology Network. http://extoxnet.orst.edu/pips/triclopy.htm

Fairchild, D. 1938. The World Was My Garden: Travels of a Plant Explorer. Charles Scribner's Sons, New York.

Ferriter, A. 2001. Lygodium Management Plan for South Florida. Florida exotic pest plant council Lygodium task force. 
Gardener, D.E. 1993. Plant Pathogens as Biocontrol agents. Pp. 4321-451.In C.P. Stone, C.W. Smith and J.T. Tunison. Alien Plant Invasions in Native Ecosysytems of Hawaii: Management and Research. Honolulu, Howaii.

Glass, R.L. 1987. Phosphate adsorption by soils and clay minerals. Journal of Agricultural Food Chemistry 35(4):497-500.

Glyphosate Herbicide Fact Sheet, Journal of Pesticide Reform, Winter 2004, Vol. 24 , No. 4

Greathead, D.J. 1995. Benefits and risks of classical biocontrol. Pp 53-63 In H.M. Hokken and J.M. Lynch (eds.) Biological control: benefits and risks. Cambridge University Press, U.K.

Gray, A. 1879. The pertinacity and predominance of weeds. American Journal of Science and Arts 18: 161-167

Grosu, R., and A. Hulea. 1973. Morphogenesis, sporogenesis, and cultural and physiological features of $M$. verrucaria. Rev. Roum. Biol. Ser. Bot. 18: 219-225.

Hance, R. J. 1976. Adsorption of glyphosate by soils. Pestic. Sci. 7:363-366

Harley, K.L.S. and I.W. Forno. 1992. Biological control of Weeds. A handbook for Practitioners and Students. Inkata Press, Melbourne.

Herbicide fact sheet. Glyphosate. Journal of herbicide reform. Winter 2004. vol24. no4.

Holdsworth, D.K. 1974. A Phytochemical survey of the Medicinal plants of the d'Entrecasteaux Islands, Papua. Sci. in New Guinea 2: 164-171.

Kenfield, D., G. Bunkers, G.A. Strobel and F. Sugawara. 1998. Potential new herbicides phytotoxins from plant pathogens. Weed Technology 2:519-524

Kourtev, P.S., J.G. Ehrenfeld, and M. Häggblom. 2002. Exotic plant species alter the microbial community structure and function in the soil. Ecology. 83 (11): 3152-3166.

Kruger, F.J., D.M. Richardson, and B.W. van Wilgen. 1986. Processes of invasion by alien plants. Pp. 145-155. In. A.W. McDonald, K. J. Kruger and A.A. Ferrar (eds.) The ecology and management of biological invasions in southern Africa. Oxford University Press. Cape Town. South Africa.

Kuti, J.O., T.J. Ng and G.A. Bean, 1987. Reactions of muskmelon cultigens to Myrothecium roridum. Hort. Sci. 22 : 635--637 
Langeland, K.A. 1998. Help protect Florida's Natural Areas from Non-native Invasive Plants. University of Florida, Institute of Food and Agricultural Sciences. Cir.1204

Langeland, K.A. 2004. Natural Area Weeds: Old World Climbing fern (Lygodium microphyllum). University of Florida, Institute of Food and Agricultural Sciences. SS-AGR-21

Lee, C.E. 2002. Evolutionary genetics of invasive species. Trends in Ecology and Evolution. 17: 386-391

Lockwood, J.A, 1993. Environmental issues involved in biological control of rangeland grasshoppers (Orthoptera: Acrididae) with exotic agents. Environmental Entomology. 22: $504-518$

Lockwood, J.A, 1996. The ethics of biological control: Understanding the moral implications of our most powerful ecological technology. Agriculture and Human Values. 13: 2- 19

Lodge, T.E. 1998. The Everglades Handbook, Understanding the Ecosystem. CRC Press LLC, Boca Raton, Fl.

Losos, J.B., K.B. Warheit, and T.W. Schoener. 1997. Adaptive differentiation following Experimental island colonization in Anolis lizards. Nature 387: 70-73

Lott, M.S., J.C. Volin, R.W. Pemberton, and D.F. Austin. 2003. The reproductive biology of the invasive ferns Lygodium microphyllum and L. japonicum. (Schizaeaceae): Implications for invasive potential. American Journal of Botany 90 (8): 1144-1152.

Mack, R. N. 1995. Understanding the processes of weed invasions: the influence of environmental stochasticity. in: British Crop Protection Council Symposium Proceedings: weeds in a changing world 64:65-74.

Mack, R.N. et al 2000. Biotic Invasions: Causes, epidemiology, global consequences and control. Ecological Applications. 10 (3): 689-710

Mandy, T., Hurd, C., and J.M. Randall. 2001. Weed Control Methods Handbook: Tools and Techniques for Use in Natural Areas. The Nature Conservancy. 7K.3.

Maron, J.L. et al. 2004. Rapid Evolution of an Invasive Plant. Ecological Monographs 74(2): 261-280 
McArthur, E.D, A.C. Blauer, and R. Stevens. 1990. Forage Kochia competition with cheatgrass in central Utah. Symposium on Cheatgrass invasion, shrub die off, and other aspects of shrub biology and management. U. S. Forest Service General Technical Report. INT-276 Pp 56-65

McEnvoy, P.B. and E.M. Coombs. 2000. Why things bite back: unintended consequences of biological weed control. Pp. 167-194 In P.A. Follett and J.J. Duan (eds.) Nontarget effects of biological control. Kluwer Academic Publishers. Boston, Massachusetts.

Miller, J.H. 2003. Noninvasive Plants of Sothern Forests. A guide for identification and control. USDA Forest Service. Southern Research Station. Auburn, Alabama

Moody, M.E., and R.N. Mack. 1988. Controlling the spread of plant invasions: The importance of nascent foci. Journal of Applied Ecology 25: 1009-1021

Mortimer, P.A., J.D. Campbell, M.E. Di Manna, and E.P. White. 1971. Experimental Myrotheciotoxicosis and poisoning in ruminants by verrucarin $\mathrm{A}$ and roridin $\mathrm{A}$. Res. Vet. Sci. 12: $508-515$.

Nomura, N. S., and H. W. Hilton. 1977. The adsorption and degradation of glyphosate in five Hawaiian sugarcane soils. Weed Research 17:113-121.

Pemberton, R. W. and A. P. Ferriter. 1998. Old World climbing fern (Lygodium microphyllum), a dangerous invasive weed in Florida. American Fern Journal 88: 165-175.

Pemberton, R.W., J.A. Goolsby, and T. Wright. 2002. Old World Climbing Fern. In Van Driesche, R. et al Biological control of Invasive Plants in the Eastern United States. USDA Forest Service Publication FHTET-2002-04, 413p.

People and Plants online retrieved on December 16, 2004 from http://peopleandplants.org/handbook/handbook2/ethno.htm

Powell, J.M. 1976b. Part III. Ethnobotany. In Paijmans, K. ed. New Guinea vegetation. 106-183, f. 3.1, pl. 44-53. Aust. Nat. Univ. Canberra

Roberts, D. 1996. Climbing fern wreaks wetland havoc. Fla. Department of Environmental Protection Resource Management Notes 8 (1):13

Roberts, D. 1997. L. microphyllum research and mitigation at Jonathan Dickson State Park. Fla. Department of Environmental Protection Resource Management Notes 9 (2):30-32 
Rueppel, M.L., B.B. Brightwell, J. Schaefer and J.T. Marvel. 1977. Metabolism and degradation of glyphosate in soil and water. Journal of Agricultural and Food Chemistry 25:517-528.

Shrum, R.D. 1982. Creating Epiphytotics. Pp 113 -136 In Biological Control of Weeds with Plant Pathogens. R. Charudattan and H.L. Walker, eds. John Wiley, New York.

Siemann, E. and W.E. Rogers. 2003. Increased competitive ability of a an invasive tree may be limited by an invasive beetle. Ecological applications 13(6) 1503-1507

Simberloff, D., D. C. Schmitz, and T. C. Brown, eds. 1997. Strangers in Paradise: Impact and Management of non-indigenous Species in Florida. Island Press, Washington, DC.

Solis, M.A., Yen, S., Goolsby, J.A. 2004. Description and life history of Lygomusotima new genus, and Neomusotima conspurcatalis (lepidoptera: crambidae) from Australia and Southeastern Asia feeding on Lygodium microphyllum (Schizaeaceae). Annals of the Entomological Society of America. 97(1): 64-76

South Florida Ecosystem Restoration. Land Acquisition Update, Oct. 1, 2002. Retrieved on November 3, 2004 from http://www.sfrestore.org

Sprankle, P., W. F. Meggitt, and D. Penner. 1975a. Rapid inactivation of glyphosate in the soil. 1975a. Weed Science. 23(3):224-228.

Sprankle, P. W. F. Meggitt, and D. Penner. 1975b. Adsorption, mobility, and microbial degradation of glyphosate in the soil. Weed Science. 23(3):229-234.

Stone, P.A. and G.L. Chmura. 2004. Sediments, stratigraphy, and aspects of succession, chronology, and major prehistoric disturbance in the principal type of large tree islands in Shark Slough. Southeast Environmental Research Center FIU Final Report.

Strong, D.R. and R.W. Pemberton. 2000. Biological control of invading species-risks and reform. Science 288: 1969-1970

Templeton, G. E. 1982. Status of weed control with plant pathogens. Pages 29-44 in: R. Charudattan and H.L. Walker, eds., Biological Control of Weeds with Plant Pathogens. John Wiley \& Sons, Inc., New York.

Thomas Jr., B. and L.A. Brandt. 2003. Monitoring ground treatments of Old World Climbing fern (Lygodium microphyllum) on the Arthur R. Marshall Loxahatchee NWR. Pp 9-10. Wildland weeds

United States Department of Agriculture. 1978. Biological agents for pest control. Status and prospects. Washington, D.C. U.S. Government Print Office. 
United States Department of Agriculture. Environmental Assessment Silvicultural Treatments in the Apalachian Ranger District. Forest Service. June 2003

USDA Miscellaneous Publication No. 1475. Issued January 1990.

Waage, J. 1997. Global developments in biological controls and the implications for Europe. Pp 5-13 In I.M. Smith (ed.), EPPO/CABI workshop on safety and efficacy o biological control in Europe. Blackwell Science Ltd., Oxford, UK.

Wagner Jr., W.H. and A.R. Smith. 1993. Pteridophytes of North America. Ch 12. In Flora of North America Editorial Committee, eds. 1993+. Flora of North America north of Mexico. $7+$ vols. New York and Oxford.

Walker, H.L. and A.M. Tilly. 1997. Evaluation of an isolate of Myrothecium verrucaria from Sicklepod (Senna obtusifolia) as a potential mycoherbicide agent. Biological control; theory and applications in pest management. 10 (2): 104-112

Wapshere, A.J. 1974. A strategy for evaluating the safety of organisms for biological weed control. Annals of Applied Biology 77: 201-211.

Wapshere, A.J. 1989. A testing sequence for reducing rejection of potential biological control agents for weeds. Annals of Applied Biology 114: 515-526

Warrior P, Rehberger LA, Beacu M, Grau PA, Kirfman GW, Conley JM (1999). Commercial development and introduction of DiTeraTM, a new nematicide. Pesticide Science 55, 376-379.

Weber, E. and B. Schmid. 1998. Latitudinal population differentiation in two species of Solidago (Asteraceae) introduced into Europe. American Journal of Botany 85: 1110-1121

Yang, S.M. and S.C. Jong. $1995^{a}$. Host range determination of Myrothecium verrucaria isolated from leafy spurge. Plant disease. 79: 994-997.

Yang, S.M. and S.C. Jong. $1995^{b}$. Factors influencing pathogenicity of Myrothecium verrucaria isolated from Euphorbia esula a species of Euphorbia. Plant disease. 79: 998-1002.

Zidack, N.K., Backman, P.A., and Shaw, J.J. 1992. Promotion of bacterial infection of leaves by an organosilicone surfactant: Implications for biological weed control. Biological Control. 2, 111-117. 
APPENDIX I : Tests of Between-Subjects Effects in Conidial Concentration Study

\begin{tabular}{|c|c|c|c|c|c|c|}
\hline Source & $\begin{array}{c}\text { Dependent } \\
\text { Variable }\end{array}$ & $\begin{array}{l}\text { Type III } \\
\text { Sum of } \\
\text { Squares } \\
\end{array}$ & $\mathrm{df}$ & $\begin{array}{c}\text { Mean } \\
\text { Square }\end{array}$ & $F$ & Sig. \\
\hline \multirow[t]{3}{*}{$\begin{array}{l}\text { Corrected } \\
\text { Model }\end{array}$} & day $4 \mathrm{DI}$ & $4.822(\mathrm{a})$ & 2 & 2.411 & 17.616 & .000 \\
\hline & day $12 \mathrm{DI}$ & $68.889(b)$ & 2 & 34.444 & 223.703 & .000 \\
\hline & day $24 \mathrm{DI}$ & $371.667(\mathrm{c})$ & 2 & 185.833 & 740.560 & .000 \\
\hline \multirow[t]{3}{*}{ Intercept } & day $4 \mathrm{DI}$ & 9.633 & 1 & 9.633 & 70.383 & .000 \\
\hline & day $12 \mathrm{DI}$ & 120.000 & 1 & 120.000 & 779.351 & .000 \\
\hline & day 24 DI & 653.333 & 1 & 653.333 & 2603.582 & .000 \\
\hline \multirow[t]{3}{*}{ Treatment } & day 4 DI & 4.822 & 2 & 2.411 & 17.616 & .000 \\
\hline & day $12 \mathrm{DI}$ & 68.889 & 2 & 34.444 & 223.703 & .000 \\
\hline & day $24 \mathrm{DI}$ & 371.667 & 2 & 185.833 & 740.560 & .000 \\
\hline \multirow[t]{3}{*}{ Error } & day $4 \mathrm{DI}$ & 36.544 & 267 & .137 & & \\
\hline & day $12 \mathrm{DI}$ & 41.111 & 267 & .154 & & \\
\hline & day $24 \mathrm{DI}$ & 67.000 & 267 & .251 & & \\
\hline \multirow[t]{3}{*}{ Total } & day $4 \mathrm{DI}$ & 51.000 & 270 & & & \\
\hline & day $12 \mathrm{DI}$ & 230.000 & 270 & & & \\
\hline & day $24 \mathrm{DI}$ & 1092.000 & 270 & & & \\
\hline \multirow{2}{*}{$\begin{array}{l}\text { Corrected } \\
\text { Total }\end{array}$} & day 4 DI & 41.367 & 269 & & & \\
\hline & day $12 \mathrm{DI}$ & 110.000 & 269 & & & \\
\hline
\end{tabular}

a R Squared $=.117$ (Adjusted R Squared $=.110$ )

b R Squared $=.626$ (Adjusted $\mathrm{R}$ Squared $=.623$ )

c R Squared $=.847$ (Adjusted R Squared $=.846$ )

DI : Disease Index 
APPENDIX II : Comparison of severity rating of Lygodium plants between both Conidial concentrations.

\section{Pairwise Comparisons}

Measure: diseaseindex

\begin{tabular}{|c|c|c|c|c|c|c|c|}
\hline \multirow[b]{2}{*}{ Day } & \multirow[b]{2}{*}{$\begin{array}{l}\text { (I) } \\
\text { trtmt. }\end{array}$} & \multirow[b]{2}{*}{$\begin{array}{l}(\mathrm{J}) \\
\text { trtmt. }\end{array}$} & \multirow{2}{*}{$\begin{array}{c}\text { Mean } \\
\text { Difference } \\
(1-J)\end{array}$} & \multirow[b]{2}{*}{$\begin{array}{l}\text { Std. } \\
\text { Error }\end{array}$} & \multirow[b]{2}{*}{ Sig. $^{a}$} & \multicolumn{2}{|c|}{$\begin{array}{c}95 \% \text { Confidence } \\
\text { nterval for Difference }\end{array}$} \\
\hline & & & & & & $\begin{array}{l}\text { Lower } \\
\text { Bound }\end{array}$ & $\begin{array}{l}\text { Upper } \\
\text { Bound }\end{array}$ \\
\hline \multirow[t]{2}{*}{4} & 1 & 2 & .011 & .043 & .798 & -.078 & .100 \\
\hline & 2 & 1 & -.011 & .043 & .798 & -.100 & .078 \\
\hline \multirow[t]{2}{*}{12} & 1 & 2 & $.433^{\star}$ & .075 & .000 & .280 & .586 \\
\hline & 2 & 1 & $-.433^{\star}$ & .075 & .000 & -.586 & -.280 \\
\hline \multirow[t]{2}{*}{24} & 1 & 2 & $1.021^{*}$ & .092 & .000 & .833 & 1.209 \\
\hline & 2 & 1 & $-1.021^{*}$ & .092 & .000 & -1.209 & -.833 \\
\hline
\end{tabular}

Based on estimated marginal means

${ }^{*}$. The mean difference is significant at the .05 level.

a.Adjustment for multiple comparisons: Least Significant Differenc (equivalent to no adjustments).

Treatment (trtmt.)

$1: 1 \times 10^{8}$ conidial $/ \mathrm{ml}$

$2: 1 \times 10^{7}$ conidial $/ \mathrm{ml}$ 
APPENDIX III : Pairwise comparison illustrating the significant difference In daily responses among treatments.

\section{Pairwise Comparisons}

Measure: diseaseindex

\begin{tabular}{|c|c|c|c|c|c|c|c|}
\hline \multirow[b]{2}{*}{ treatment } & \multirow[b]{2}{*}{$\begin{array}{l}\text { (I) } \\
\text { day }\end{array}$} & \multirow[b]{2}{*}{$\begin{array}{l}\text { (J) } \\
\text { day }\end{array}$} & \multirow{2}{*}{$\begin{array}{c}\text { Mean } \\
\text { Difference } \\
(1-J)\end{array}$} & \multirow[b]{2}{*}{$\begin{array}{l}\text { Std. } \\
\text { Error }\end{array}$} & \multirow[b]{2}{*}{ Sig. } & \multicolumn{2}{|c|}{$\begin{array}{c}95 \% \text { Confidence } \\
\text { Interval for } \\
\text { Difference }\end{array}$} \\
\hline & & & & & & $\begin{array}{l}\text { Lower } \\
\text { Bound }\end{array}$ & $\begin{array}{l}\text { Upper } \\
\text { Bound }\end{array}$ \\
\hline \multirow{6}{*}{$\begin{array}{l}1 \times 10 \mathrm{e} 8 \\
\text { conidia/ml }\end{array}$} & 4 & 12 & $-.933^{\star}$ & .048 & .000 & -1.031 & -.835 \\
\hline & & 24 & $-2.543^{*}$ & .061 & .000 & -2.669 & -2.417 \\
\hline & 12 & 4 & $.933^{*}$ & .048 & .000 & .835 & 1.031 \\
\hline & & 24 & $-1.610^{*}$ & .064 & .000 & -1.741 & -1.480 \\
\hline & 24 & 4 & $2.543^{*}$ & .061 & .000 & 2.417 & 2.669 \\
\hline & & 12 & $1.610^{*}$ & .064 & .000 & 1.480 & 1.741 \\
\hline \multirow{6}{*}{$\begin{array}{l}1 \times 10 \mathrm{e} 7 \\
\text { conidia/ml }\end{array}$} & 4 & 12 & $-.511^{*}$ & .048 & .000 & -.609 & -.413 \\
\hline & & 24 & $-1.533^{*}$ & .061 & .000 & -1.659 & -1.408 \\
\hline & 12 & 4 & $.511^{*}$ & .048 & .000 & .413 & .609 \\
\hline & & 24 & $-1.023^{*}$ & .064 & .000 & -1.153 & -.892 \\
\hline & 24 & 4 & $1.533^{*}$ & .061 & .000 & 1.408 & 1.659 \\
\hline & & 12 & $1.023^{*}$ & .064 & .000 & .892 & 1.153 \\
\hline
\end{tabular}

Based on estimated marginal means

*. The mean difference is significant at the .05 level.

a. Adjustment for multiple comparisons: Least Significant Difference (equivalent to no adjustments). 
APPENDIX IV: Tests of Within-Subjects Contrasts between the two environmental factors over time.

\begin{tabular}{|c|c|c|c|c|c|c|c|}
\hline Source & days & \begin{tabular}{|l|} 
Type III \\
Sum of \\
Squares \\
\end{tabular} & $\mathrm{df}$ & $\begin{array}{l}\text { Mean } \\
\text { Square } \\
\end{array}$ & $\mathrm{F}$ & Sig. & $\begin{array}{l}\text { Partial } \\
\text { Eta } \\
\text { Squared } \\
\end{array}$ \\
\hline \multirow[t]{2}{*}{ days } & Linear & 120.333 & 1 & 120.333 & 702.128 & .000 & .768 \\
\hline & Quadratic & .198 & 1 & .198 & 1.543 & .216 & .007 \\
\hline \multirow{2}{*}{$\begin{array}{l}\text { days * } \\
\text { Temp }\end{array}$} & Linear & 2.370 & 1 & 2.370 & 13.831 & .000 & .061 \\
\hline & Quadratic & .012 & 1 & .012 & .096 & .756 & .000 \\
\hline $\begin{array}{l}\text { days * } \\
\text { Humidity }\end{array}$ & Linear & .148 & 1 & .148 & .864 & .354 & .004 \\
\hline \multirow{3}{*}{$\begin{array}{l}\text { days * } \\
\text { Temp * } \\
\text { Humidity }\end{array}$} & Quadratic & .111 & 1 & .111 & .868 & .353 & .004 \\
\hline & Linear & 1.815 & 1 & 1.815 & 10.589 & .001 & .048 \\
\hline & Quadratic & .198 & 1 & .198 & 1.543 & .216 & .007 \\
\hline \multirow[t]{2}{*}{ Error day } & Linear & 36.333 & 212 & .171 & & & \\
\hline & Quadratic & 27.148 & 212 & .128 & & & \\
\hline
\end{tabular}


APPENDIX V : Tests of Between-Subjects Effects (Temperature and Humidity)

Transformed Variable: Average

\begin{tabular}{|l|l|c|c|c|c|c|}
\hline Source & $\begin{array}{l}\text { Type III } \\
\text { Sum of } \\
\text { Squares }\end{array}$ & df & $\begin{array}{c}\text { Mean } \\
\text { Square }\end{array}$ & F & Sig. & $\begin{array}{c}\text { Partial Eta } \\
\text { Squared }\end{array}$ \\
\hline Intercept & 1981.002 & 1 & 1981.002 & 2718.919 & .000 & .928 \\
Temperature & 161.002 & 1 & 161.002 & 220.974 & .000 & .510 \\
Humidity & 238.347 & 1 & 238.347 & 327.131 & .000 & .607 \\
$\begin{array}{l}\text { Temperature } * \\
\text { Humidity }\end{array}$ & 103.520 & 1 & 103.520 & 142.081 & .000 & .401 \\
Error & 154.463 & 212 & .729 & & & \\
\hline
\end{tabular}


APPENDIX VI : Measure of Mean Severity rating of test plants in Growth Chamber

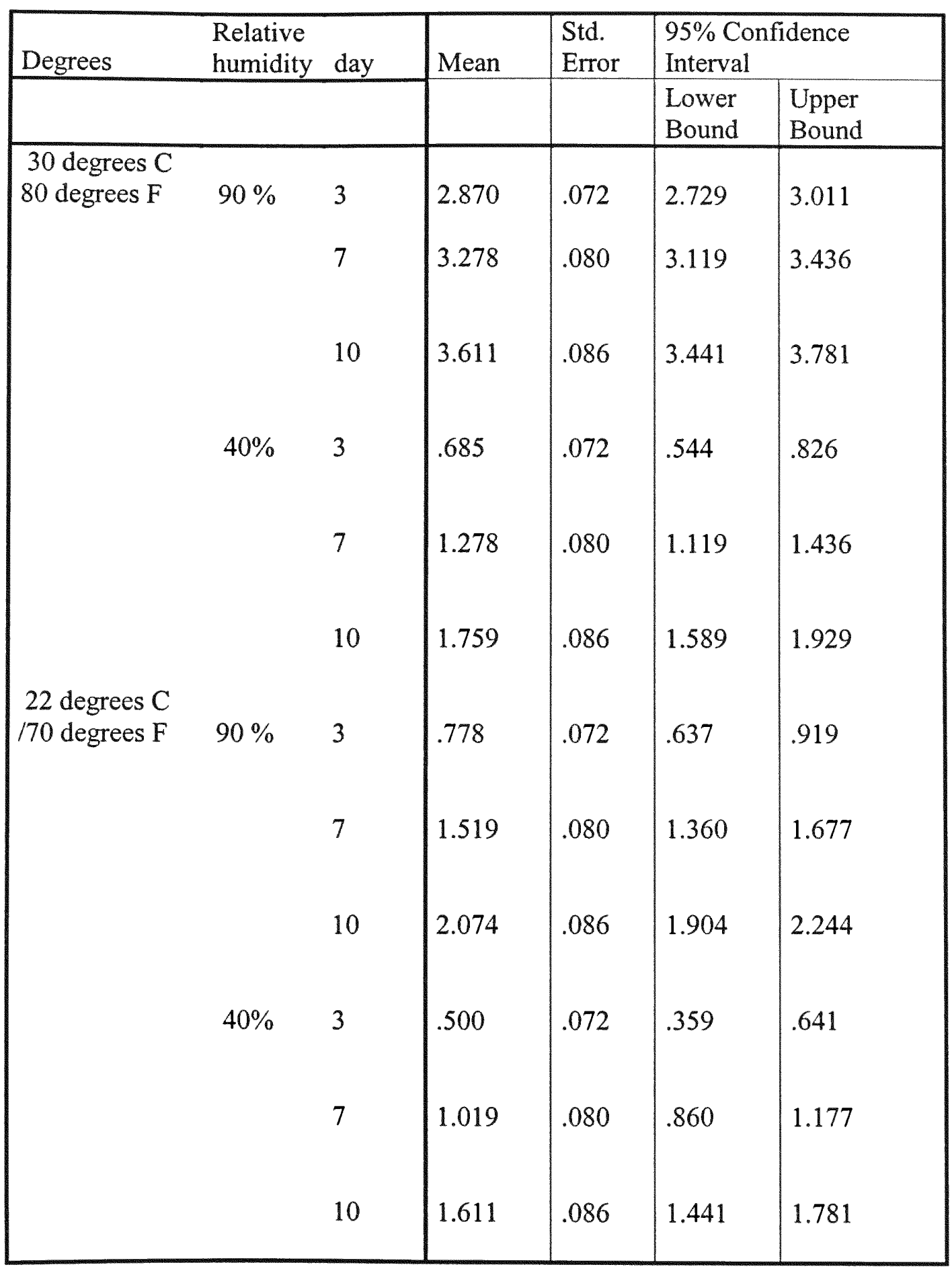


APPENDIX VII : Univariate Tests for Humidity in Growth Chamber Study

\begin{tabular}{|c|c|c|c|c|c|c|c|c|}
\hline $\begin{array}{l}\text { Relative } \\
\text { humidit } \\
\text { y }\end{array}$ & day & & $\begin{array}{l}\text { Sum of } \\
\text { Squares }\end{array}$ & df & $\begin{array}{l}\text { Mean } \\
\text { Square }\end{array}$ & $\mathrm{F}$ & Sig. & $\begin{array}{l}\text { Partial } \\
\text { Eta Sqd. }\end{array}$ \\
\hline $90 \%$ & 3 & Contrast & $\begin{array}{r}118.2 \\
31\end{array}$ & 1 & $\begin{array}{r}118.2 \\
31\end{array}$ & 427.921 & .000 & .669 \\
\hline & & Error & 58.574 & 212 & .276 & & & \\
\hline & 7 & Contrast & 83.565 & 1 & 83.565 & 238.983 & .000 & .530 \\
\hline & & Error & 74.130 & 212 & .350 & & & \\
\hline & 10 & Contrast & 63.787 & 1 & 63.787 & 158.643 & .000 & .428 \\
\hline 9 & & Error & 85.241 & 212 & .402 & & & \\
\hline & 3 & Contrast & .926 & 1 & .926 & 3.351 & .069 & .016 \\
\hline & & Error & 58.574 & 212 & .276 & & & \\
\hline & 7 & Contrast & 1.815 & 1 & 1.815 & 5.190 & .024 & .024 \\
\hline & & Error & 74.130 & 212 & .350 & & & \\
\hline & 10 & Contrast & .593 & 1 & .593 & 1.474 & .226 & .007 \\
\hline & & Error & 85.241 & 212 & .402 & & & \\
\hline
\end{tabular}

Each $\mathrm{F}$ tests the simple effects of Degrees within each level combination of the other effects shown. These tests are based on the linearly independent pairwise comparisons among the estimated marginal means. 
APPENDIX VIII : Univariate Tests for Temperature in Growth Chamber Study

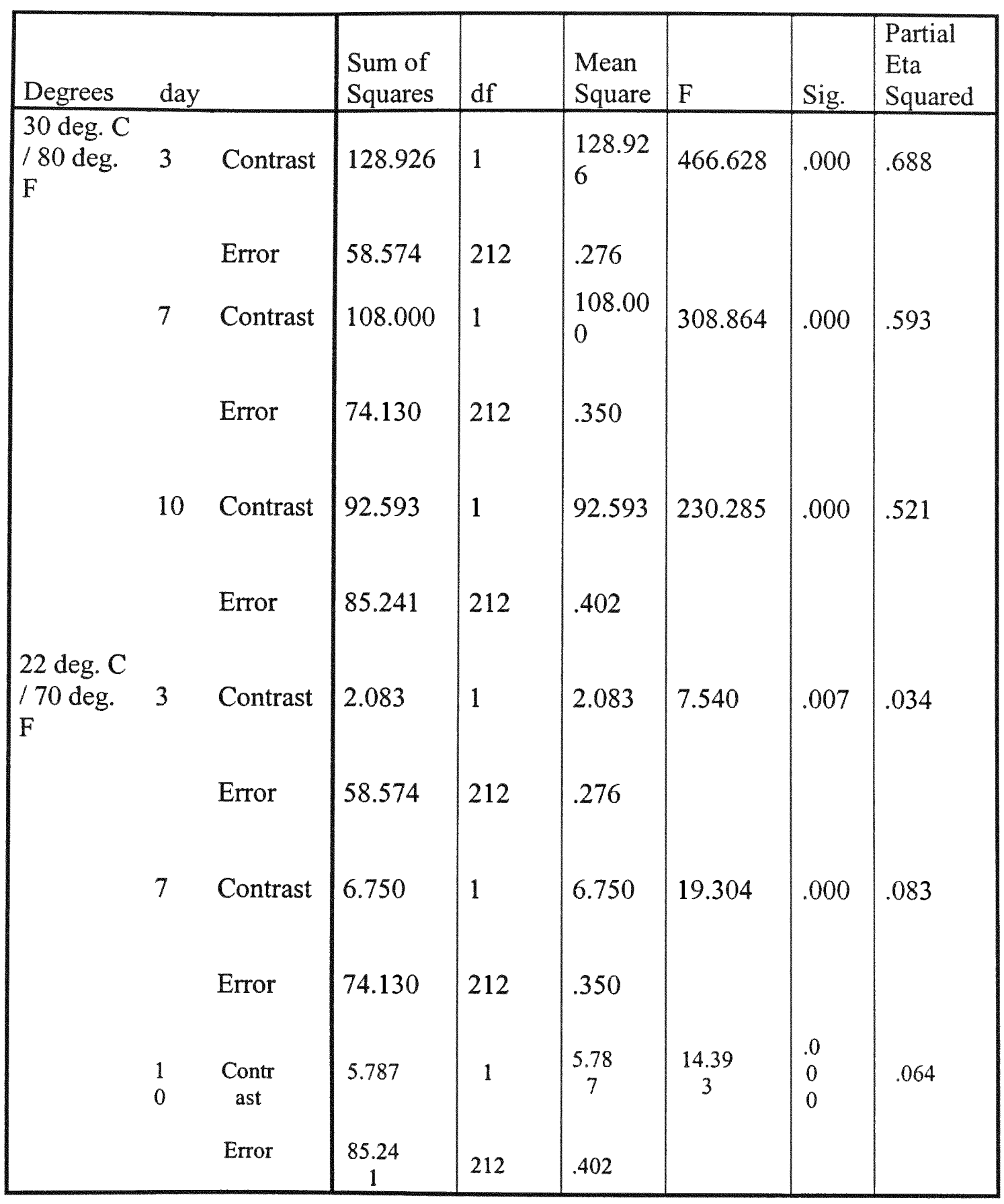

Each $\mathrm{F}$ tests the simple effects of Relative humidity within each level combination of the other effects shown. These tests are based on the linearly independent pairwise comparisons among the estimated marginal means. 
APPENDIX IX: Estimated marginal mean severity rating of $M$. verrucaria at $40 \%$ relative humidity and varying temperatures.

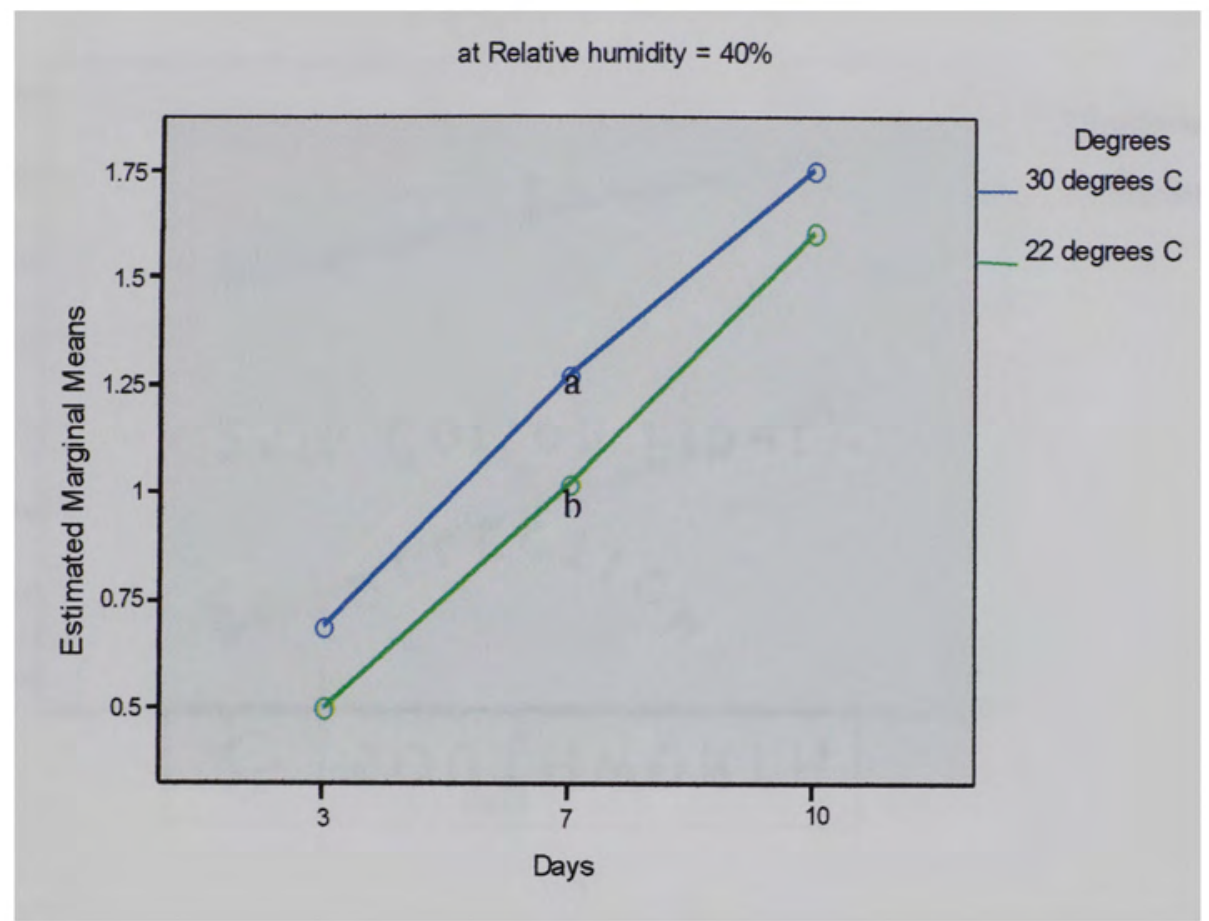


APPENDIX X: Estimated marginal mean severity rating of $M$. verrucaria at $90 \%$ relative humidity and varying temperatures.

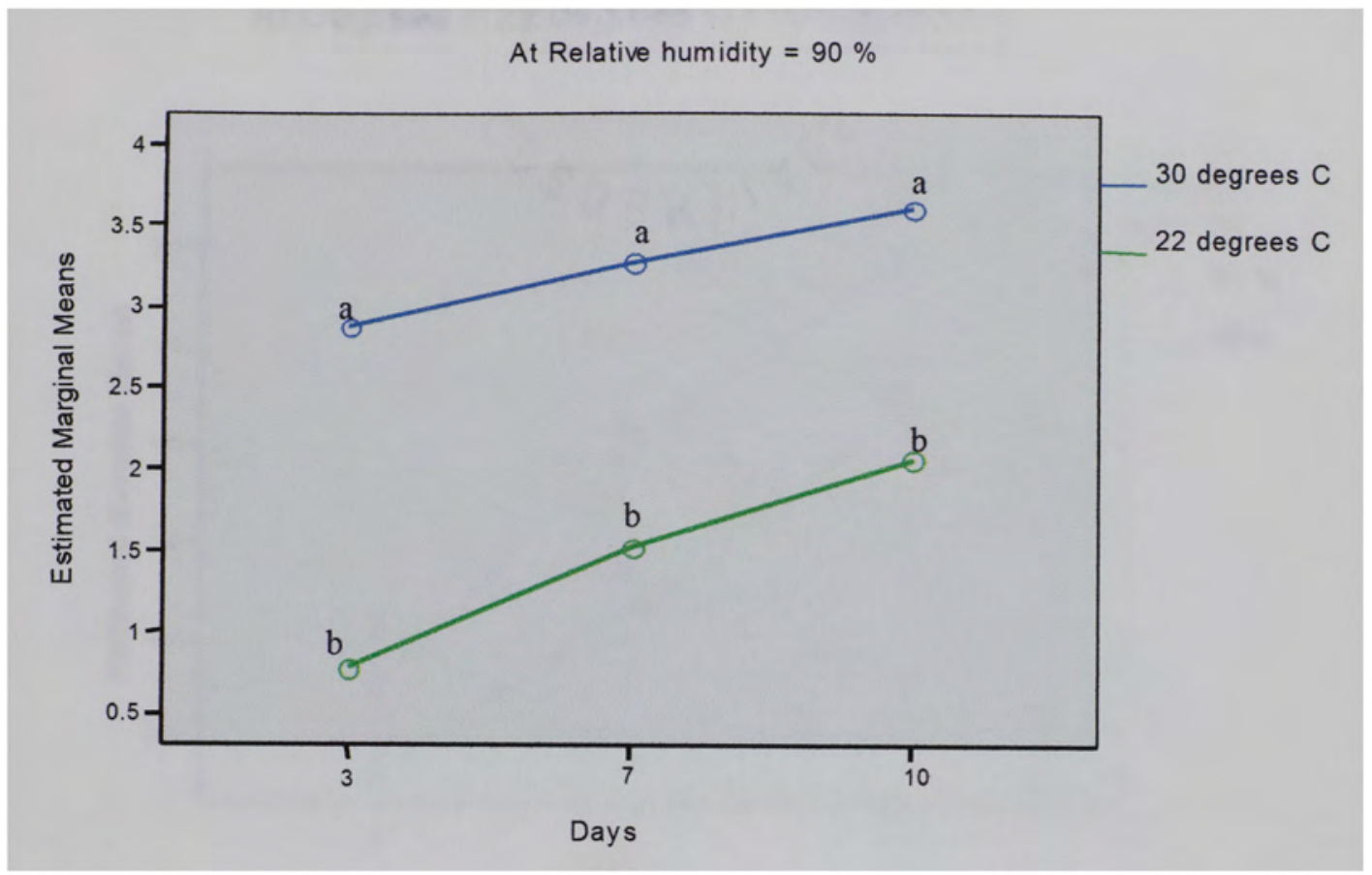


Appendix XI : Comparative effect of $M$. verrucaria on L. microphyllum at $70^{\circ} \mathrm{F}$ And $40 \%$ and $90 \%$ humidity over time.

At Degrees $=22$ degrees $\mathrm{C} / 70$ degrees $\mathrm{F}$

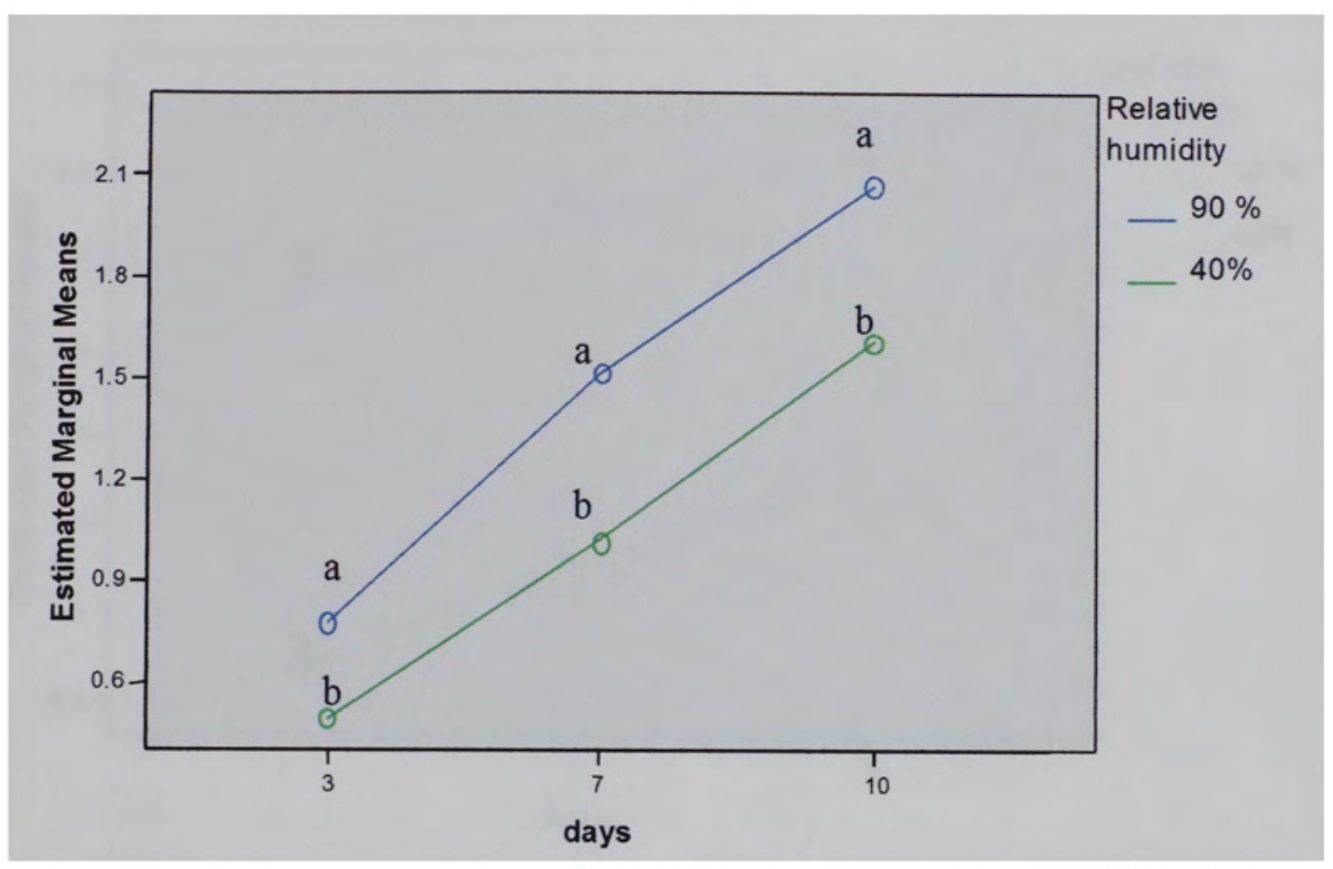


APPENDIX XII: Comparative effect of M. verrucaria on L. microphyllum at $80^{\circ} \mathrm{F}$ And $40 \%$ and $90 \%$ humidity over time.

At Degrees $=30$ degrees $\mathrm{C} / 80$ degrees $\mathrm{F}$

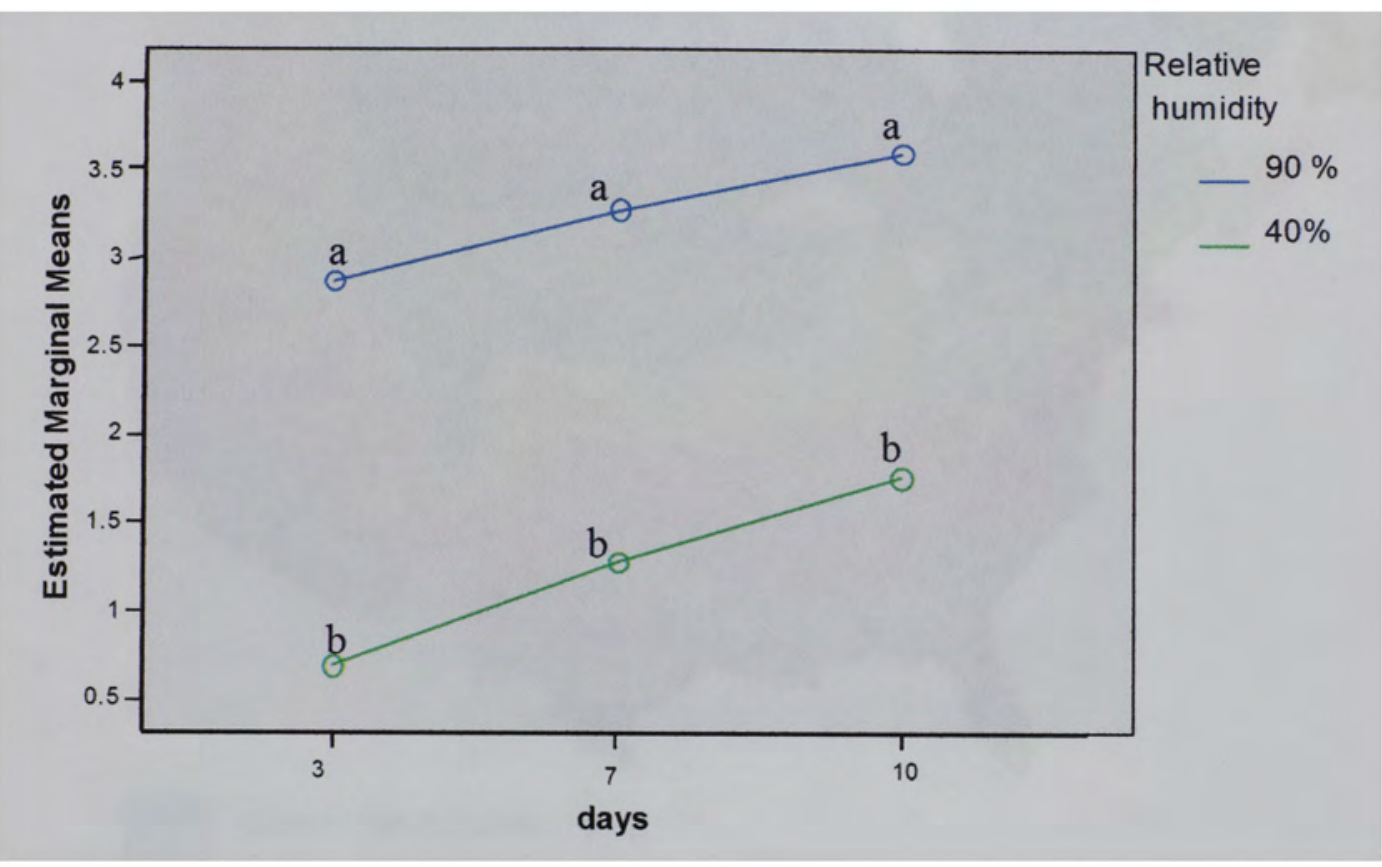




\section{APPENDIX XIII: Plant Hardiness Zone Map}

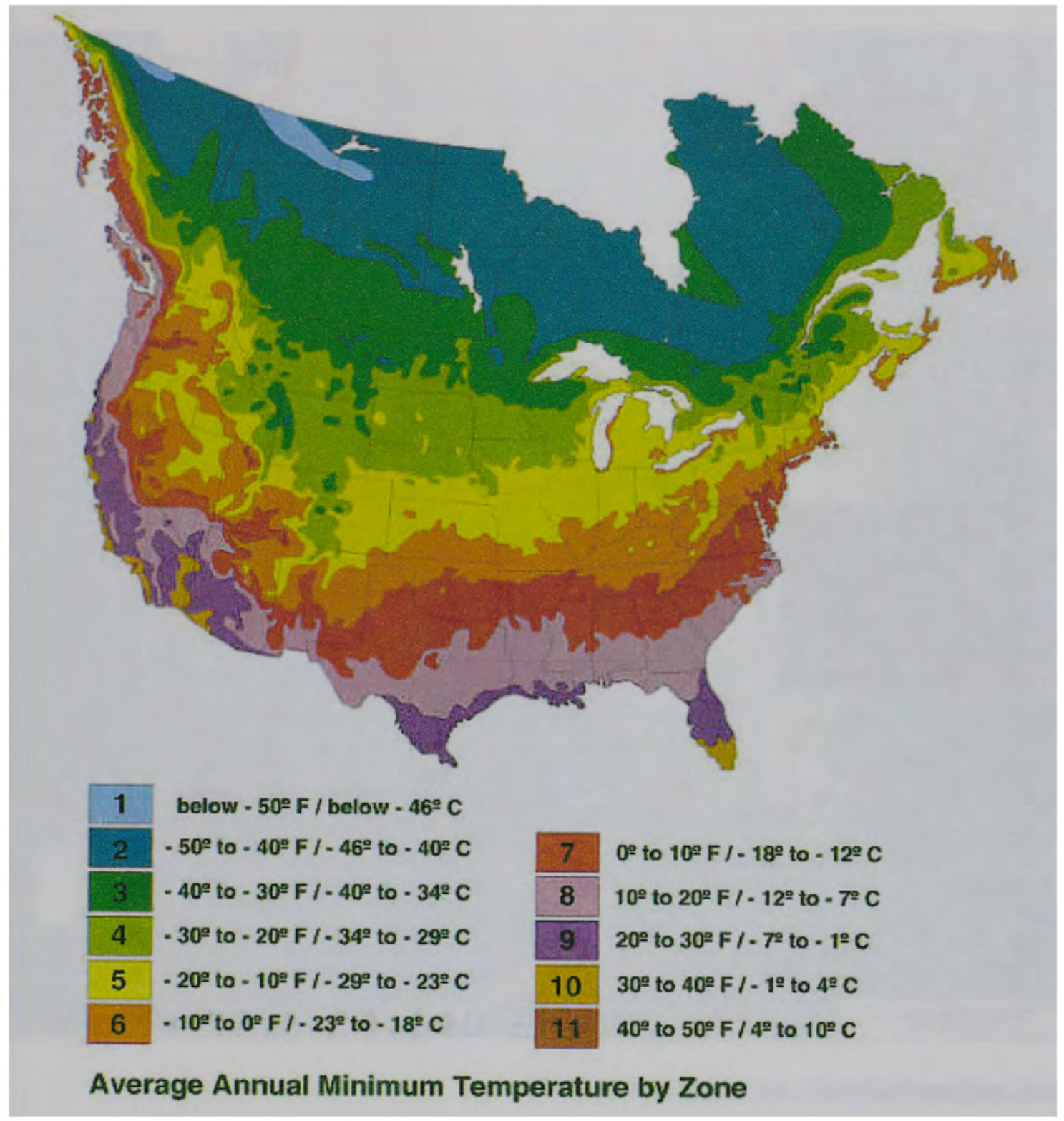




\section{APPENDIX XIV: Map of South Florida illustrating location of field sites}

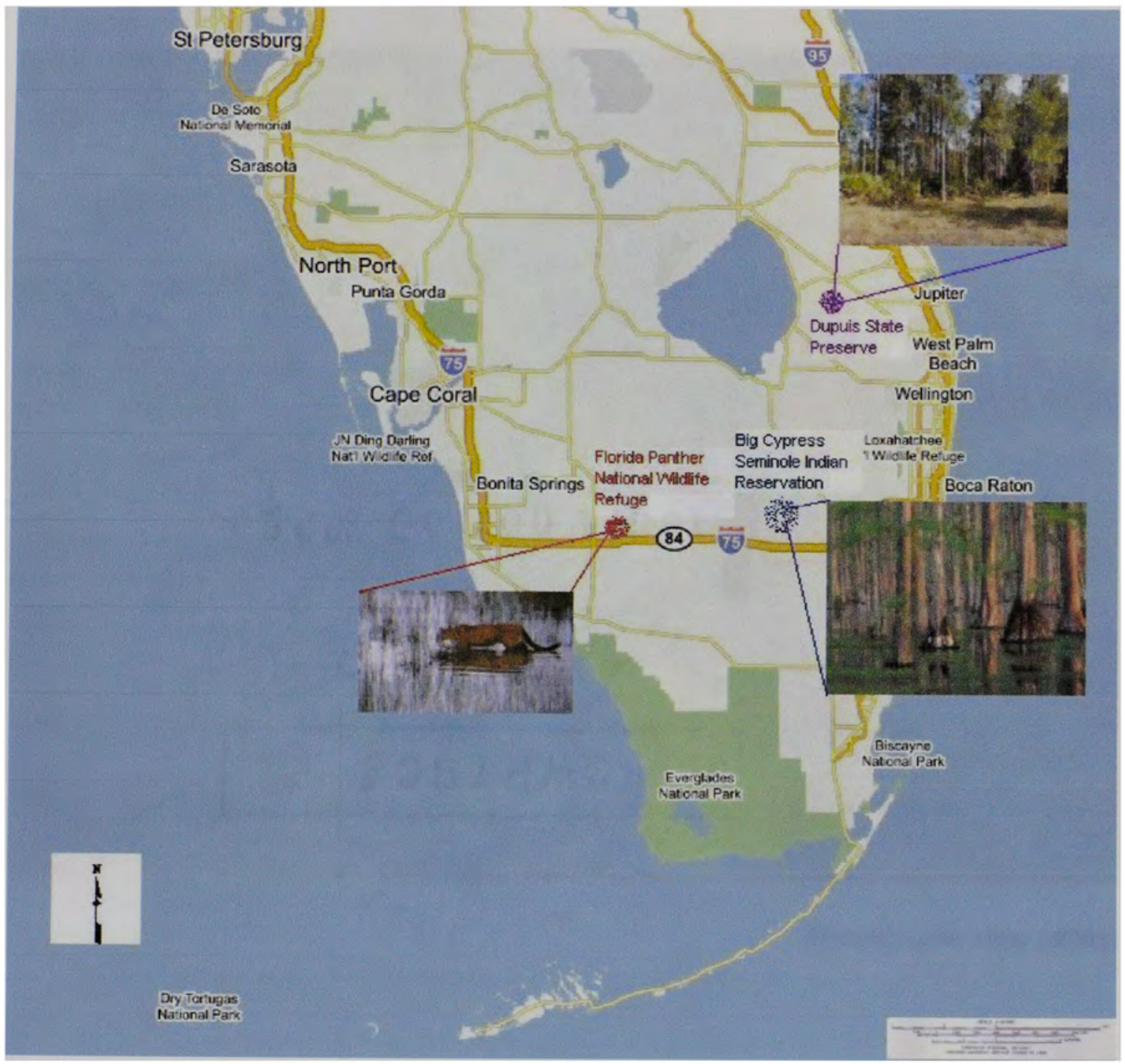

Modified from http://www.roseandearl.com/map.html 
APPENDIX XV: Myrothecium verrucaria hyphae inside an infected

Lygodium microphyllum leaf tissue

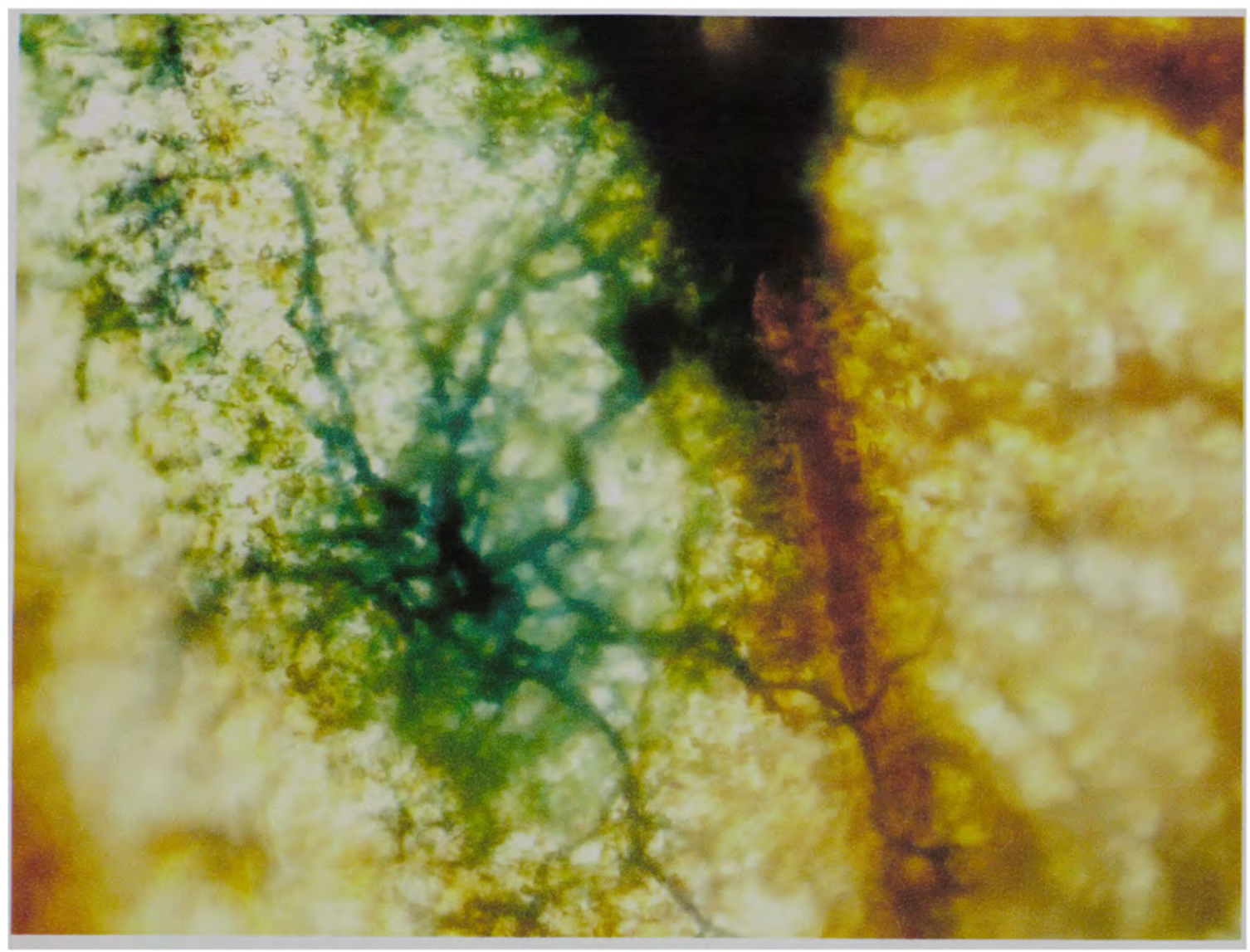

Microscopic view (400x) 